\title{
The Disruptive Blockchain: Types, Platforms and Applications
}

\author{
Article by Mahendra Kumar Shrivas ${ }^{1,}$ Dr. Thomas Yeboah ${ }^{2}$ \\ ${ }^{I}$ Research Scholar, School of Information Technology, Texila American University, Guyana, South \\ America \\ ${ }^{2}$ Head of Department, Department of ICT Christian Service University College, Kumasi, Ghana \\ E-mail: ${ }^{1}$ mshrivas@texilaconnect.com ${ }^{2}$ tyeboah@csuc.edu.gh
}

\begin{abstract}
Organizations with high motivation for growth and cost-effective operation efficiencies, are always trying to bring new technologies to their operations. These organizations are very sensitive to change and value driven thus constant change is the only law for them to achieve their goals and to be in the market. When Bitcoin jumps into the market, the whole world wanted to own it but now after Bitcoin and Cryptocurrency bubble, there are significant shift towards Blockchain related products, services, solution developments, researches and use-case studies. From technical-financial opportunist, to evangelist, to researchers, to Tech enterprises, to financial institutions, to governments, the whole world is behind Blockchain and now it has the technological spot light. Blockchain has left behind all other technologies as far as research initiatives, investments and financial funding are concern. There are substantial research growth on, how Blockchain can be useful in specific area? Objectives of this paper are to highlight some facts about Blockchain that were misinterpreted and misrepresented due to this sudden shift. In this research article, authors are presenting comprehensive literature review of Blockchain Technologies and its applications in various sectors. Our research supports that Blockchain is revolutionizing and disrupting organizations across all industries. Blockchain is really a next big technological invention after Internet. In Blockchain Code is the law and Smart Contracts are the new way of doing business.
\end{abstract}

Keywords: Blockchain, Permissioned, Permission less, Smart Contract, Bitcoin, Ethereum, Hyperledger Fabric, Corda R3, Quorum, IOTA, Ripple, Kadena, Tezos, Sawlooth, NEM, MultiChain, HydraChain, BigChainDB, OpenChain.

\section{Introduction}

Industrial revolution, computer revolution and power of internet have transformed various economies in the past and were main driving force of growth. Today we are in the next transition phase, new technologies like Cloud Computing, Big Data, Internet of Things (IoT), Artificial Intelligence (AI), Machine Learning (ML), Quantum Computing, etc. are going become de facto standard of next era of driving force of economic growth and Blockchain is going to be integral part of all technologies.

Blockchain was originally used in Bitcoin by a pseudonym called Satoshi Nakamoto in 2009, which is a digital cryptocurrency. Blockchain facilitates transfer of digital currency between parties without need of any central bank or intermediator in Bitcoin network (Shrivas \& Yeboah, 2017; Nofer, Gomber, Hinz, \& Schiereck, 2017; Tama, Kweka, Park, \& Rhee, 2017). While Bitcoin is designed to store state of ownership of coins, Ethereum can be used to store state of ownership of any items in digital form using smart contracts (Dinh, et al., 2017).

Blockchain is just two-decade-old young disruptive technology and now getting popularity after success of Cryptocurrency. Most of the facts about Blockchain are either exaggerated, misinterpreted, little known or still unknown. The main objectives of this paper are to highlight some important phenomena about Blockchain that were misinterpreted and misrepresented. Exploratory research methodology is used in this comprehensive research study. The Standard Exploratory Method Type I, Exploratory method type 5 and 6 (Swedberg, 2018) were employed to explore various Blockchain related concepts. We tried to explore all 
DOI: $10.21522 /$ TIJAR.2014.SE.19.01.Art003

ISSN: $2520-3088$

possible secondary sources to understand Blockchain related phenomena. We explored thousands of resources mainly research articles from Google Scholar, IEEE Explore, Whitepapers, Discussion forums, Websites, Blogs, Developer Documentations from Blockchain Projects, Project Codes from GitHub, etc. and presented it in this publishable research paper (Miscione, Ziolkowski, Zavolokina, \& Schwabe, 2018). In the exploration phase we used all possible key combination like "Blockchain and Open Chain", "Blockchain and Project Funding", etc. in search query and choose most relevant and reliable source for the study.

This paper has been organized in various sections. Section II focuses on Blockchain and types while Blockchain Platform reference architecture and Blockchain platforms have been discussed in Section III. Section IV covers current and future status of financial infusion and Blockchain project initiatives while there is detailed discussion on applications of Blockchain in Section V. Conclusion is given in Section VI at the end.

\section{Blockchain and types}

A distributed ledger that holds collection of interlinked blocks along with block hash is called Blockchain (Shrivas \& Yeboah, 2017). Blockchain is distributed registry, which records transactional data blocks initiated by participating notes in the Blockchain network. Block is basic unit in Blockchain, which is generally combinations of block header and block data as depicted in Figure 1. Block header generally holds information like current block hash, root hash, timestamp, nonce, previous block hash while block data portion contains total number of transaction, transaction details (sender address, value being transfer, receiver address, transaction fee, etc.) (Dinh, et al., 2017; Zheng Z. , Xie, Dai, Chen, \& Wang, 2017; Fernàndez-València, Caube, \& Vila, 2018). A cryptographic hash algorithm like SHA-256, SHA2-512, SHA-256d (Glabb, Imbert, Jullien, Tisserand, \& Veyrat-Charvillon, 2007), SHA3-256 (Dworkin, 2015), SHAKE256, Winternitz hash (Buchmann, Dahmen, Ereth, Hülsing, \& Rückert, 2011), BLAKE2 (Patent No. IETF RFC 7693, 2015), Keccak256 (Bertoni, Daemen, Peeters, \& Assche, 2009), Scrypt (Patent No. No. RFC 7914, 2016), etc. is used to generate hash value of block that is stored in the block. Therefore, each blocks hold the value of either current block \& previous block or only previous block hash (Tama, Kweka, Park, \& Rhee, 2017). Each blocks are inter-linked in Blockchain generally by Merkle tree or acyclic directed graph, etc. and can be retrieved using underline protocol scheme. Figure 1 shows sample Block structure, while Figure 2 represent sample blocks in Blockchain, which is high level and general representation to understand Blockchain architecture. Hash values are unique for blocks thus it is very hard to change block data once it is recorded in the distributed Blockchain. Firstly, Blockchain is distributed, so if anyone wanted to change any one block, they have to alter the records everywhere and secondly they have to change all forward blocks because change in one block will generate a different hash causing different hash value for all foremost blocks, which require consent of all participating parties and required lots of computing power. This makes Blockchain transparent, temper proof, and ensure trust between parties. Third parties, intermediary or agents can be eliminated using Blockchain thus Blockchain just not ensure trust between parties but also help in lowering down the cost. Blockchain allows participants to query each transaction or transaction paths thus each transactions can be traceable from originating address/note to receiver address/node from tamperproof-distributed records.

\begin{tabular}{|c|c|c|c|c|c|}
\hline \multicolumn{6}{|c|}{ Block Header } \\
\hline Block Hash & Tree Root Hash & Timestamp & Nonce & Previous Block Hash & Other Metadata \\
\hline \multicolumn{6}{|c|}{ Block Data } \\
\hline \multicolumn{2}{|c|}{ Transaction Counter } & \multicolumn{2}{|c|}{ Total Block Value } & \multicolumn{2}{|c|}{ Total Block TX Fee } \\
\hline Transaction(TX1) & Transaction(TX2) & Transaction(TX3) & Transaction(TX4) & Transaction(TX5) & Transaction(TXn) \\
\hline Sender Address & Sender Address & Sender Address & Sender Address & Sender Address & Sender Address \\
\hline Value & Value & Value & Value & Value & Value \\
\hline TX1 Fee & TX2 Fee & TX3 Fee & TX4 Fee & TX5 Fee & TXn Fee \\
\hline Receiver Address & Receiver Address & Receiver Address & Receiver Address & Receiver Address & Receiver Address \\
\hline
\end{tabular}


Figure-1. Sample Block Structure

\begin{tabular}{|c|c|c|c|c|c|c|c|}
\hline \multicolumn{2}{|c|}{ Block Header } & & \multicolumn{2}{|c|}{ Block Header } & & \multicolumn{2}{|c|}{ Block Header } \\
\hline Block Hash(N-1) & Block Hash of (N-2) & & Block Hash(N) & Block Hash of (N-1) & & Block Hash(N+1) & Block Hash of (N) \\
\hline \multicolumn{2}{|c|}{ Block Data } & & \multicolumn{2}{|c|}{ Block Data } & & \multicolumn{2}{|c|}{ Block Data } \\
\hline \multicolumn{2}{|c|}{ Transactions } & & Tra & ions & & \multicolumn{2}{|c|}{ Transactions } \\
\hline Transaction[TX1] & Transaction[TXn] & Link & Transaction[TX1] & Transaction[ $[\mathrm{TXn}]$ & Link & Transaction[ $[\mathrm{TX} 1]$ & Transaction[TXn] \\
\hline Sender Address & Sender Add ress & & Sender Add ress & Sender Address & & Sender Address & Sender Address \\
\hline Value & Value & & Value & Value & & Value & Value \\
\hline TX1 Fee & TXn Fee & & TX1 Fee & TXn Fee & & TX1 Fee & TXn Fee \\
\hline Receiver Address & Receiver Add ress & & Receiver Add ress & Receiver Address & & Receiver Address & Receiver Ad dress \\
\hline
\end{tabular}

Figure-2. Sample Blocks in Blockchain

\section{Blockchain types}

Based on the nature of data accessibility (Lin \& Liao, 2017) Blockchain can be categories as below

1. Public Blockchain: - In this type of Blockchain, anyone one can read and submit transaction.

2. Private Blockchain: - In this type of Blockchain only one organization or all subsidiary organization within same group are allowed to read and submit transaction.

3. Community/Consortium Blockchain: - In this type of Blockchain multiple group of organizations form a consortium and are allowed to submit transactions and read transactional data.

4. Hybrid Blockchain: - This is new category where any of three Public, Private or Community/Consortium, Blockchain can be combined to facilitate transactions. A Blockchain platform can be configured in multi-mode using Hybrid Blockchain.

Based on the need of authorization to participate in Blockchain it can be categories (Michael, Cohn, \& Butcher, 2018) as below

1. Permission less Blockchain: - No prior permission is needed to participate in this type of Blockchain, everyone allowed to participate in verification process and can join Blockchain network with their own computational power.

2. Permissioned Blockchain: - To join this type of Blockchain prior permission is needed. Only authorized parties are allowed to run nodes to verify transactions in Blockchain network.

3. Hybrid Blockchain: - There could be possibility that a node is participating in Permission less and Permissioned Blockchain together to facilitate inter-Blockchain communication such Blockchain can be called Hybrid Blockchain. A Blockchain platform can also be configured to support Permissioned and/or Permission less model.

As far as core functionality and smart contract support in concern, Blockchain can be categories (Hileman \& Rauchs, 2017) into following: -

1. Stateless Blockchain: - Stateless Blockchain system only focus on transaction optimization and chain functionality that is verifying the transaction by computing hashes. It is independent from smart contract logic layer thus unaffected from smart contract code bugs and vulnerabilities.

2. Stateful Blockchain: - This type of Blockchain provide smart contract logic optimization along with optimized transaction computing capabilities.

\section{Blockchain platforms}

Blockchain is emerging technology and reaching to maturity as adoption is growing. Bitcoin was the first Blockchain powered platform launched in 2009 and was designed to exchange digital cryptocurrency without any need of central authority. Bitcoin revolutionizes exchange of money by using distributed technology and cannot counterfeited due to strong cryptographic protocol and hash function. New coins can only be generated by mining process as a reward for solving computation hashes and verifying transactions (Zheng Z. , Xie, Dai, \& Wang, 2016). 
DOI: $10.21522 /$ TIJAR.2014.SE.19.01.Art003

ISSN: $2520-3088$

In last one decade there are various Blockchain platforms that are somehow similar to Blockchain platform but with added functionalities, have been developed. Blockchain platform is core of Blockchain network and provides key services to participating nodes. A typical Blockchain platform (Cloud Standards Customer Council, 2017) should have following modules as depicted in Figure 3:-

1. Blockchain Runtime Environment: - To be able to process Blockchain transactions and smart contracts Blockchain needed a secure hosting environment. Generally secure operating system, programming language, runtime libraries and supporting libraries reside in this layer.

2. Cryptographic Services: - This layer provides access to cryptographic algorithms like hash function, digital signature, etc.

3. Smart Contract Module: - Smart contract module is optional and only applicable to Stateful Blockchain. It encapsulates business logics that can be implemented using programming language like go, solidity, java, Rust, $\mathrm{C}++$, etc.

4. Blockchain Secondary Storage: - Blockchain platform process high amount of transactions and needs highly secure, reliable and scalable storage solution to store block data in Blockchain distributed ledger. This layer provides permanent storage capabilities to platform. Generally Level DB, Rocks DB, H2 Database, Mongo DB is being used as storage along with other distributed data storage solutions to store ledger information.

5. Blockchain Memory Store: - This layer stores latest transactions in memory for faster data retrieval and to speed up the transaction execution. Merkle Tree, Trie, Acyclic Directed Graph, Associative Array, etc. are some of the data structures that are being used as a memory storage in various Blockchain platforms.

6. Consensus Protocol Module: - This module contains mechanism to achieve agreement between nodes about transaction validity and authenticity. Once majority of nodes are agree and consensus level is achieved then the given transaction is treated as valid and recorded in the distributed ledger. Proof of Service (Pow), Proof of Stake (PoS), Proof of Importance (PoI), Raft, Byzantine Fault Tolerance (BFT), etc. are some of the famous Blockchain Consensus Protocol in use.

7. Blockchain Services Layer: - Using this layer Blockchain platforms can be leverage with extra capabilities such as membership management, authorization and access management, event distribution and notification services, exposing platform services using Application Programing Interface (API), etc. However, some of the services like membership management, authorization, access management, etc. are mean only for Permissioned Blockchain and not applicable to Permission less Blockchain.

8. Communication Protocol: Blockchain Protocol implements standard rules that facilitates distributed peer-to-peer communication between participating nodes in Blockchain network. Bitcoin uses broadcasting over TCP connection (Bitcoin Community, 2018) and Hyperledger Fabric is powered by a gossip data dissemination protocol (Hyperledger, 2018) while Ethereum uses devp2p protocol (Ethereum Community, 2018).

Generally, users send transaction to a node in Blockchain network. The Node groups set of transactions into one block and then broadcast this Block to all nodes for processing. Nodes compute cryptographic hashes, process Blockchain transactions, and broadcast success result to all Nodes in Blockchain network. Based on Consensus and agreement block is added to distributed ledger and transaction is completed successfully. In case of Bitcoin and Ethereum the node that is successfully verified the transaction is rewarded and this process is called mining.

Table 1 shows most popular Blockchain Platforms and its categorization while Blockchain Platforms and its technical specifications have been pretested in Table 2. 


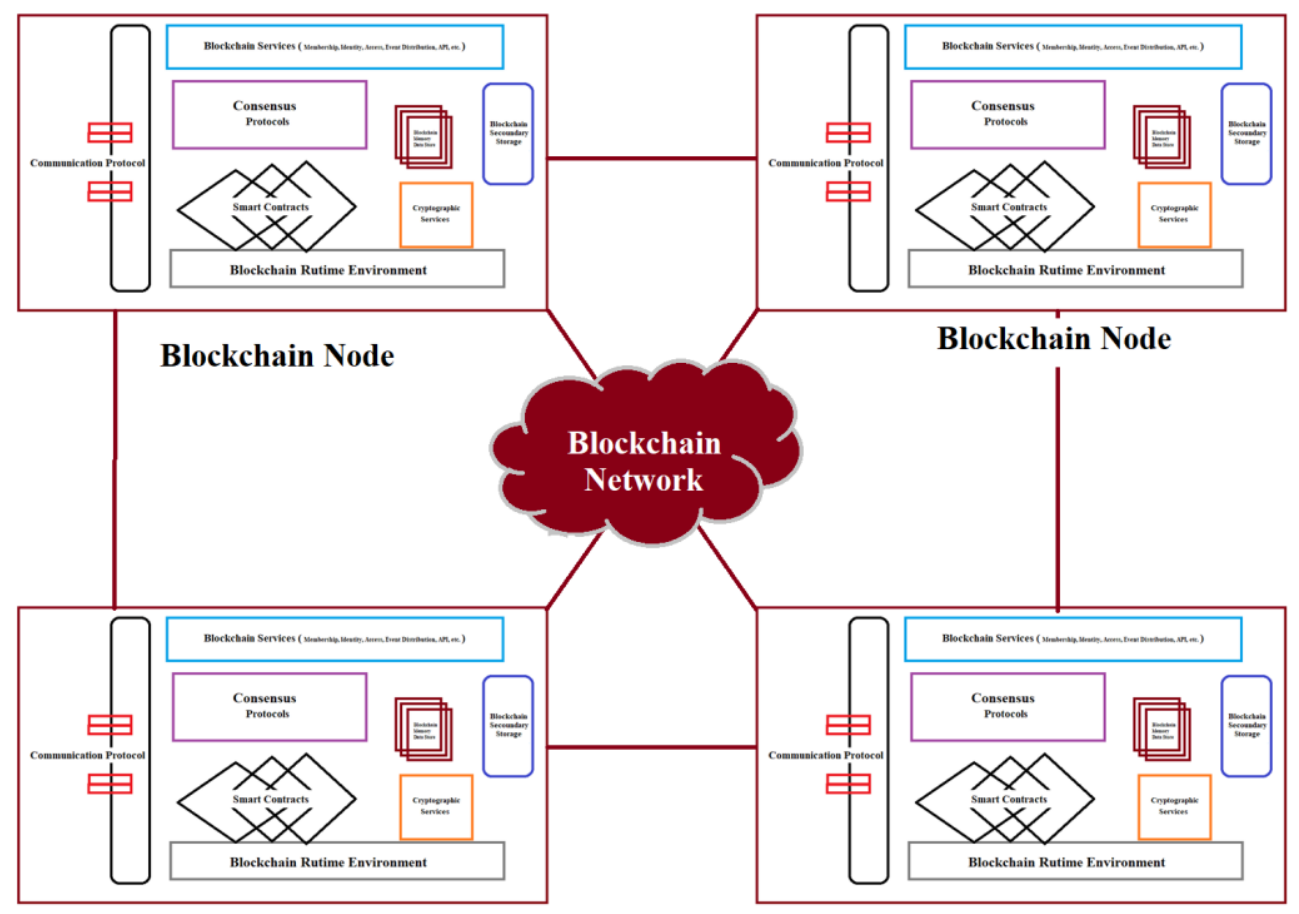

Blockchain Node

Blockchain Node

Figure 3. Sample high-level blockchain and network architecture

Table 1. Blockchain Platform and Categorization

\begin{tabular}{|l|l|l|l|l|l|l|}
\hline S.N. & $\begin{array}{l}\text { Blockchain } \\
\text { Platform }\end{array}$ & $\begin{array}{l}\text { Start } \\
\text { Year }\end{array}$ & $\begin{array}{l}\text { Category } \\
\mathbf{1} \\
\text { (Private/P } \\
\text { ublic/Cons } \\
\text { ortium/Hy } \\
\text { brid) }\end{array}$ & $\begin{array}{l}\text { Category 2 } \\
\text { (Permission } \\
\text { less/Permissione } \\
\text { d/Hybrid) }\end{array}$ & $\begin{array}{l}\text { Category 3 } \\
\text { (Stateless/Statef } \\
\text { ul) }\end{array}$ & Project Website \\
\hline 1 & Bitcoin & 2009 & Public & Permission less & Stateless & $\begin{array}{l}\text { https://bitcoincore.or } \\
\text { g https://bitcoin.org }\end{array}$ \\
\hline 2 & Ethereum & 2015 & Public & Permission less & Stateful & https://ethereum.org/ \\
\hline 3 & $\begin{array}{l}\text { Hyperledger } \\
\text { Fabric }\end{array}$ & 2016 & $\begin{array}{l}\text { Consortiu } \\
\text { m }\end{array}$ & Permissioned & Stateful & $\begin{array}{l}\text { https://www.hyperled } \\
\text { ger.org/ }\end{array}$ \\
\hline 4 & Corda R3 & 2015 & $\begin{array}{l}\text { Consortiu } \\
\mathrm{m}\end{array}$ & Permissioned & Stateful & $\begin{array}{l}\text { https://www.corda.ne } \\
\text { t/ }\end{array}$ \\
\hline 5 & Quorum & 2016 & $\begin{array}{l}\text { Consortiu } \\
\text { m }\end{array}$ & Permissioned & Stateful & $\begin{array}{l}\text { https://www.jpmorga } \\
\text {.com/global/Quoru } \\
\mathrm{m}\end{array}$ \\
\hline 6 & IOTA & 2015 & Public & Permission less & Stateless & https://www.iota.org/ \\
\hline 7 & Ripple & 2012 & $\begin{array}{l}\text { Consortiu } \\
\mathrm{m}\end{array}$ & Permissioned & Stateless & https://ripple.com/ \\
\hline 8 & Kadena & 2016 & Hybrid & Hybrid & Stateful & https://kadena.io \\
\hline 9 & Tezos & 2018 & Public & Permissioned & Stateful & https://tzscan.io \\
\hline
\end{tabular}


DOI: $10.21522 /$ TIJAR.2014.SE.19.01.Art003

ISSN: $2520-3088$

\begin{tabular}{|l|l|l|l|l|l|l|}
\cline { 5 - 6 } 10 & Sawlooth & 2016 & Hybrid & Hybrid & Stateful & $\begin{array}{l}\text { https://www.hyperled } \\
\text { ger.org/projects/sawt } \\
\text { ooth }\end{array}$ \\
\hline 11 & NEM & 2015 & Hybrid & Hybrid & Stateless & https://nem.io/ \\
\hline 12 & Multi Chain & 2015 & Private & Permissioned & Stateless & $\begin{array}{l}\text { https://www.multicha } \\
\text { in.com }\end{array}$ \\
\hline 13 & $\begin{array}{l}\text { Hydra } \\
\text { Chain }\end{array}$ & 2016 & Hybrid & Hybrid & Stateful & $\begin{array}{l}\text { https://github.com/H } \\
\text { ydraChain }\end{array}$ \\
\hline 14 & $\begin{array}{l}\text { Big } \\
\text { ChainDB }\end{array}$ & 2016 & Hybrid & Hybrid & Stateless & $\begin{array}{l}\text { https://www.bigchain } \\
\text { db.com }\end{array}$ \\
\hline 15 & Open Chain & 2015 & Hybrid & Hybrid & Stateless & $\begin{array}{l}\text { https://www.opencha } \\
\text { in.org/ }\end{array}$ \\
\hline
\end{tabular}

Table 2. Blockchain platform and technical specification

\begin{tabular}{|c|c|c|c|c|c|c|}
\hline $\begin{array}{l}\text { S.N } \\
\text { o. }\end{array}$ & $\begin{array}{l}\text { Blockchain } \\
\text { Platform }\end{array}$ & $\begin{array}{l}\text { Hash } \\
\text { Function }\end{array}$ & $\begin{array}{l}\text { In Memory } \\
\text { Data } \\
\text { Structure }\end{array}$ & $\begin{array}{l}\text { Secondary } \\
\text { Storage }\end{array}$ & $\begin{array}{l}\text { Consensus } \\
\text { Protocol }\end{array}$ & $\begin{array}{l}\text { Programm } \\
\text { ing } \\
\text { Languages }\end{array}$ \\
\hline 1 & Bitcoin & SHA-256 & Merkle Tree & Level DB & Proof of Work & $\mathrm{C}++$ \\
\hline 2 & Ethereum & Keccak256 & Trie & $\begin{array}{l}\text { Level DB, } \\
\text { Rocks DB }\end{array}$ & $\begin{array}{l}\text { Proof of Work } \\
\text { (Ethash) }\end{array}$ & $\begin{array}{l}\text { Go, C++, } \\
\text { Rust, } \\
\text { Solidity }\end{array}$ \\
\hline 3 & $\begin{array}{l}\text { Hyperledger } \\
\text { Fabric }\end{array}$ & $\begin{array}{l}\text { SHA3 } \\
\text { SHAKE256 }\end{array}$ & $\begin{array}{l}\text { Bucket-tree, } \\
\text { Merkle Tree }\end{array}$ & Rocks DB & $\begin{array}{l}\text { Supports } \\
\text { pluggable } \\
\text { consensus like } \\
\text { Practical } \\
\text { Byzantine Fault } \\
\text { Tolerance } \\
\text { (PBFT), Raft, } \\
\text { PoW, PoS }\end{array}$ & $\begin{array}{l}\text { Go, } \\
\text { JavaScript, } \\
\text { Java }\end{array}$ \\
\hline 4 & Corda R3 & SHA-256 & Merkle tree & H2 database & $\begin{array}{l}\text { Validity } \\
\text { consensus, } \\
\text { Uniqueness } \\
\text { consensus, } \\
\text { pluggable } \\
\text { consensus }\end{array}$ & Java, Kotlin \\
\hline 5 & Quorum & Keccak256 & Trie & Level DB & $\begin{array}{l}\text { QuorumChain } \\
\text { pluggable } \\
\text { consensus (PoS, } \\
\text { Raft, Istanbul - } \\
\text { BFT) }\end{array}$ & Go \\
\hline 6 & IOTA & $\begin{array}{l}\text { Winternitz } \\
\text { hash }\end{array}$ & $\begin{array}{l}\text { Acyclic } \\
\text { Directed Graph }\end{array}$ & $\begin{array}{l}\text { Trytes, } \\
\text { Balanced } \\
\text { Trinary } \\
\text { System } \\
\end{array}$ & PoW & $\begin{array}{l}\text { Go, C, } \\
\text { C++, Java, } \\
\text { JavaScript }\end{array}$ \\
\hline 7 & Ripple & SHA2-512 & $\begin{array}{l}\text { Merkle Tree, } \\
\text { Knowledge } \\
\text { Grap }\end{array}$ & $\begin{array}{l}\text { Rocks DB, } \\
\text { NuDB }\end{array}$ & $\begin{array}{l}\text { XRP Ledger } \\
\text { Consensus } \\
\text { Protocol }\end{array}$ & $\begin{array}{l}\mathrm{C}++, \\
\text { JavaScript }\end{array}$ \\
\hline 8 & Kadena & BLAKE2 & Merkle & Oracle & $\begin{array}{l}\text { BFT Raft, } \\
\text { ScalableBFT }\end{array}$ & Pact \\
\hline
\end{tabular}


Texila International Journal of Academic Research

Special Edition Apr 2019

\begin{tabular}{|l|l|l|l|l|l|l|}
9 & Tezos & $\begin{array}{l}\text { SHA- } \\
256, \text { BLAKE } \\
2\end{array}$ & Merkle & $\begin{array}{l}\text { Distributed } \\
\text { Database }\end{array}$ & Proof-of-Stake & Michelson \\
\hline 10 & Sawlooth & $\begin{array}{l}\text { SHA- } \\
512, \text { SHA25 } \\
6\end{array}$ & $\begin{array}{l}\text { BlockCache, } \\
\text { Radix Merkle } \\
\text { Tree }\end{array}$ & BlockStore & $\begin{array}{l}\text { Pluggable } \\
\text { consensus } \\
\text { algorithms } \\
\text { Proof of Elapsed } \\
\text { Time (PoET), } \\
\text { PoW, PBFT }\end{array}$ & $\begin{array}{l}\text { Rust, } \\
\text { Python, } \\
\text { JavaScript, } \\
\text { Go, C++, } \\
\text { Java }\end{array}$ \\
\hline 11 & NEM & SHA-256d & $\begin{array}{l}\text { Web, Portable } \\
\text { or Network } \\
\text { database }\end{array}$ & $\begin{array}{l}\text { Web } \\
\text { Database, } \\
\text { Access } \\
\text { database }\end{array}$ & $\begin{array}{l}\text { Proof of } \\
\text { Importance }\end{array}$ & Java, C++ \\
\hline 12 & Multi Chain & SHA3-256 & Merkle Tree & Level DB & PoW & C++ \\
\hline 13 & Hydra Chain & SHA3-256 & Merkle tree & Level DB & PBFT & Python \\
\hline 14 & Big ChainDB & SHA3-256 & $\begin{array}{l}\text { Associative } \\
\text { Array }\end{array}$ & $\begin{array}{l}\text { Mongo DB } \\
\text { Brathon, }\end{array}$ & JavaScript, \\
\hline 15 & Open Chain & SHA-256 & $\begin{array}{l}\text { Associative } \\
\text { Array }\end{array}$ & $\begin{array}{l}\text { SQLite, } \\
\text { SqlServer, } \\
\text { Mongo DB }\end{array}$ & Proof of Work & C\# \\
\hline
\end{tabular}

\section{Blockchain current and future status}

Blockchain has left behind all other technologies as far as research initiatives, investments and financial funding are concern. Resource ready Cloud Computing platforms are also fueling adoption of Blockchain. Blockchain-as-a-Service (BaaS) is new service offering category after SaaS, PaaS and IaaS from various Cloud Computing providers (Hiran, Henten, Shrivas, \& Doshi, 2018).

Blockchain is going to generate new business value of $\$ 176$ billion by 2025 , which will grow to $\$ 3.1$ trillion by 2030 further (Lovelock, Reynolds, Granetto, \& Kandaswamy, 2017). Value generation of Blockchain in 2030 is greater than individual Gross Domestic Product (GDP) of France (2.6 trillion), United Kingdom (2.6 trillion) and India (2.4 trillion) (statista.com, 2018) in 2017.

\section{A. Financial infusion and project initiatives}

As per PricewaterhouseCoopers (PwC) 2018 survey with 600 global executives $84 \%$ of executives were actively involved with Blockchain. As per the survey, various organizations reported their Blockchain based project status as $20 \%$ research stage, $32 \%$ development stage, $10 \%$ Pilot stage and $15 \%$ projects were live. In First five-month of 2018, various start-ups \& market leaders raised $\$ 13.7$ billion for Blockchain based products and services via Initial Coin Offerings (ICOs). Industry wide Blockchain leadership were reported as Financial services $46 \%$, Industrial products and manufacturing 12\%, Energy and utilities 12\%, Healthcare $11 \%$, Government $8 \%$, Retail and consumer $4 \%$ while Entertainment and media $1 \%$ (PricewaterhouseCoopers (PwC) Ltd., 2018).

In another global survey on Blockchain in 2018 by Deloitte found Blockchain working use-case Supply chain 53\%, Internet of Things 51\%, Digital identity 50\%, Digital records 44\%, Digital currency 40\%, Payments 30\% and Voting 12\%. Organizations from Canada (36\%), China (49\%), France (37\%), Germany (36\%), Mexico (48\%), United Kingdom (40\%) and United States (14\%) reported that Blockchain is currently in production. While Organizations from Canada (51\%), China (86\%), France (44\%), Germany (40\%), Mexico (56\%), United Kingdom (49\%) and United States (24\%) are investing in hiring staff with Blockchain experience now and in the future (Pawczuk, Massey, \& Schatsky, 2018). 
DOI: 10.21522/TIJAR.2014.SE.19.01.Art003

ISSN: $2520-3088$

Figure 4 suggests that Various Venture capital firms have invested total \$1,222 million in 558 companies. While they have funded total 295, Blockchain projects in last 12 months. As per Figure 4 New York (NY) gets highest amount of \$268 million investment followed by Menlo Park (CA) \$163 million, San Francisco (CA) \$125 million and Beijing (China) \$102 million and where top four city getting funding from Venture Capital firms respectively. Beijing (China) gets 48 highest number of funding for Blockchain projects followed by Palo Alto (CA) 44, New York (NY) 41 and Menlo Park (CA) 33 projects. While Venture Capitals firms have funded total 121 projects in New York, 83 projects in San Francisco, 63 projects in Menlo Park and 57 projects in Beijing.

Complete names of projects/organizations who have get funding from Venture capital firms have been given in Appendices A - Top 50 Venture Capital Firms Investing in Blockchain Project/Organization). While Figure 5 shows data of top 50 global public companies, their fortune. Public companies from various countries are aggressively working on Blockchain use cases. Top 50 global public companies with total $\$ 11,678.1$ billion market valuation and $\$ 44,089$ billion assets are generating yearly sales volume of $\$ 5,505.1$ billion and making $\$ 661.2$ billion profits yearly. All these top public companies are exploring Blockchain and pumping huge money in Blockchain related technologies. Public companies from China and United States are showstopper in this Blockchain play as depicted in Figure 5.

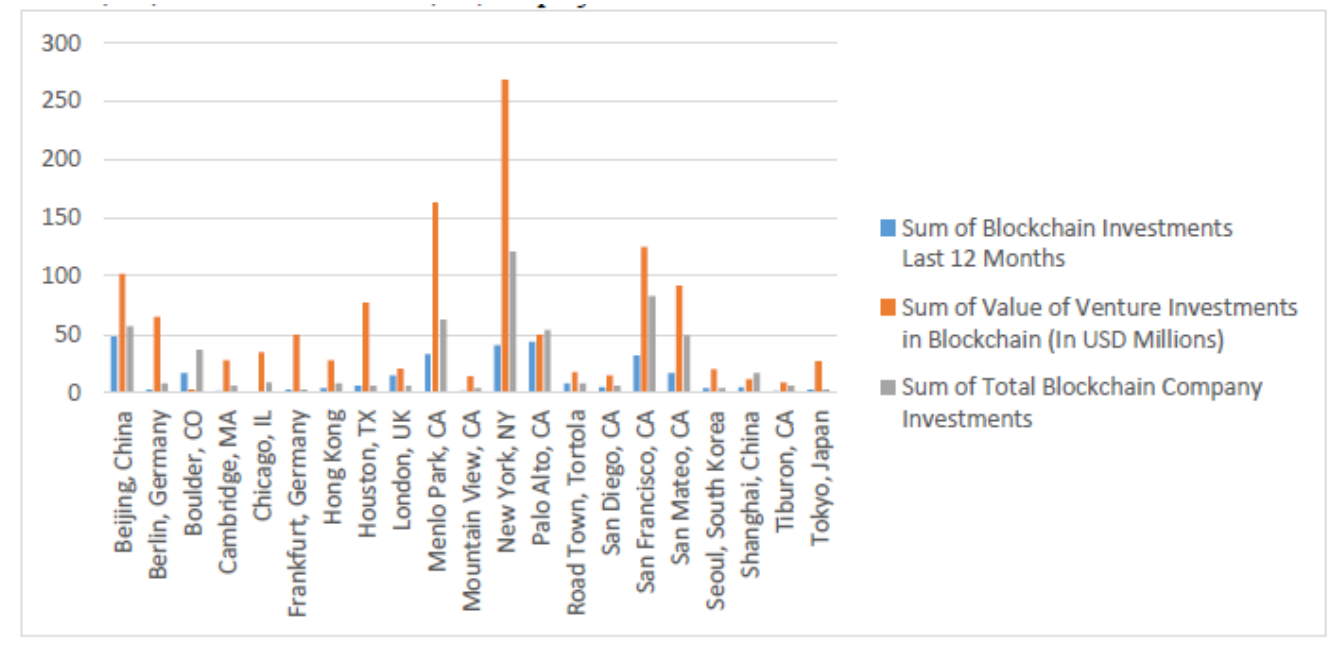

Figure 4. City wise Investment by Venture Capital Firm in Blockchain Projects (through 15 June 2018)

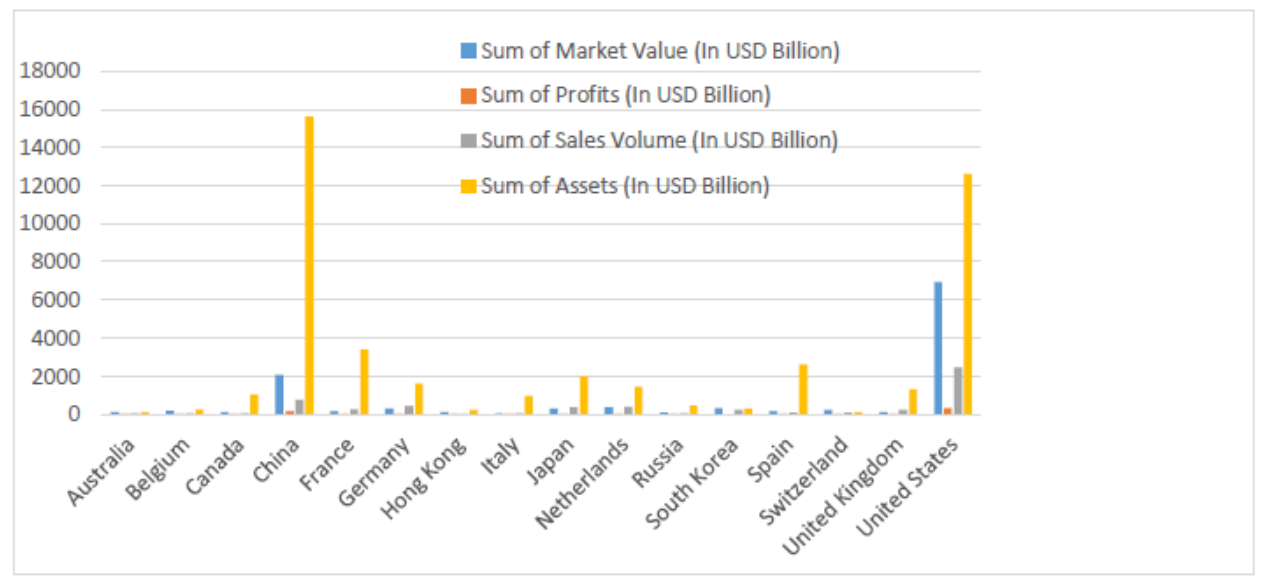

Figure 5. Country wise financial of Top 50 Global Public Companies investing in Blockchain

\section{B. Human capital}


Human capital is very important factors to sustain growth and achieve technological maturity specifically in Blockchain like young technology. As being the new and evolving technology, there are huge demand of skilled human resources in Blockchain sector. There is huge gap in supply and demand. China has evolved as global hub of Blockchain based investment while United States has largest number of Blockchain developer communities followed by India. Top five country wise total estimated Blockchain developers head count stood as 27,876(US), 12,509(India), 7,656(UK), 4,544(Canada) and 4,283(France) as depicted in Figure 6 (Filatov, 2018).

There is huge demand of Blockchain related skills in job market. As per Burning Glass Technologies in 2016, there were 1,838 job openings, that grew to 3,958 job opening, clocking $115 \%$ job growth (Bittle, 2017). As per Indeed.com Blockchain based job openings increased by $207 \%$ in 2016-2017. While demand for Blockchain engineers has grown up 700\% from Jan-2017 to Jan-2018. Job openings grown-up from 1,037 jobs in December 2016 to 4,541 job opening in Dec. 2017 on LinkedIn (HowToToken Team, 2018). At the time of writing this article, there were total 13,831 active job openings Worldwide in LinkedIn while industry wise distribution of job opening were Information Technology and Services (9205), Computer Software (8566), Financial Services (4798), Internet (4047), Staffing and Recruiting (1659), Hospital \& Health Care (163), Insurance (135), Computer Hardware (112), Investment Management (92), FundRaising (15). Job Function wise job openings were Information Technology (7875), Engineering (5236), Business Development (998), Marketing (911), Finance (672), Writing/Editing (321), Product Management (296), Human Resources (168), Administrative (114) and other (1547). While Location wise job openings recorded as United States (4042), United Kingdom (1417), London, United Kingdom (1042), Germany (933), Netherlands (761), Greater New York City Area (711), India (590), Amsterdam Area, Netherlands (318), Hong Kong (197) and Chennai Area, India (35). As per Figure 7 Malta is having highest 46 Blockchain developers per 100K Population followed by Luxembourg 36 developers, Singapore 36 developers, Switzerland 24 developers and Netherlands 19 developers respectively. Blockchain development is hottest skills and demands has grown more than $6000 \%$ within a year as far as Blockchain related Freelancing work is concern. In Free Launching job market specialist are making between $\$ 50$ to $\$ 150$ per hours based on their experience level while Blockchain full time developer earns between $\$ 50 \mathrm{~K}$ and $\$ 180 \mathrm{~K}$ yearly (Mearian, 2018). Apart from technical skills demand there are significant demand for Marketing Manager, Community Manager, Relations Manager, Product Manager, Risk Analyst, etc. (Walters, 2018).

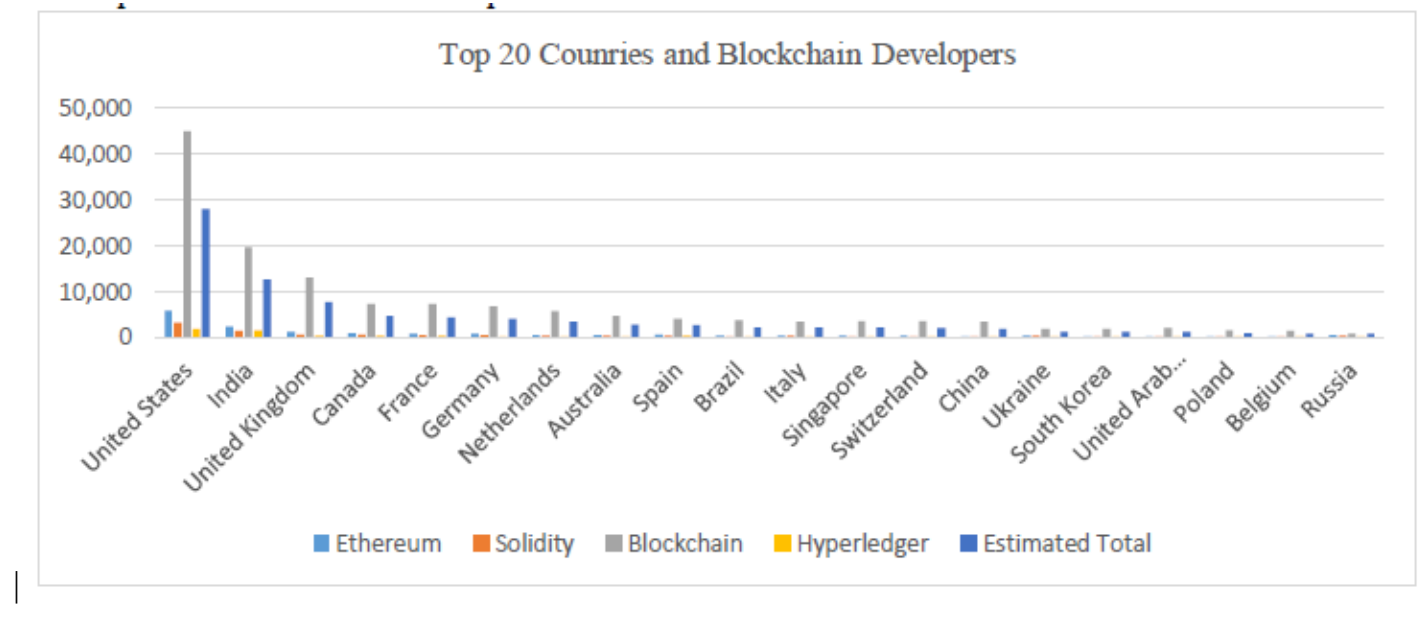

Figure 6. Global blockchain developers counts (Top 20 Countries) 
DOI: $10.21522 /$ TIJAR.2014.SE.19.01.Art003

ISSN: $2520-3088$

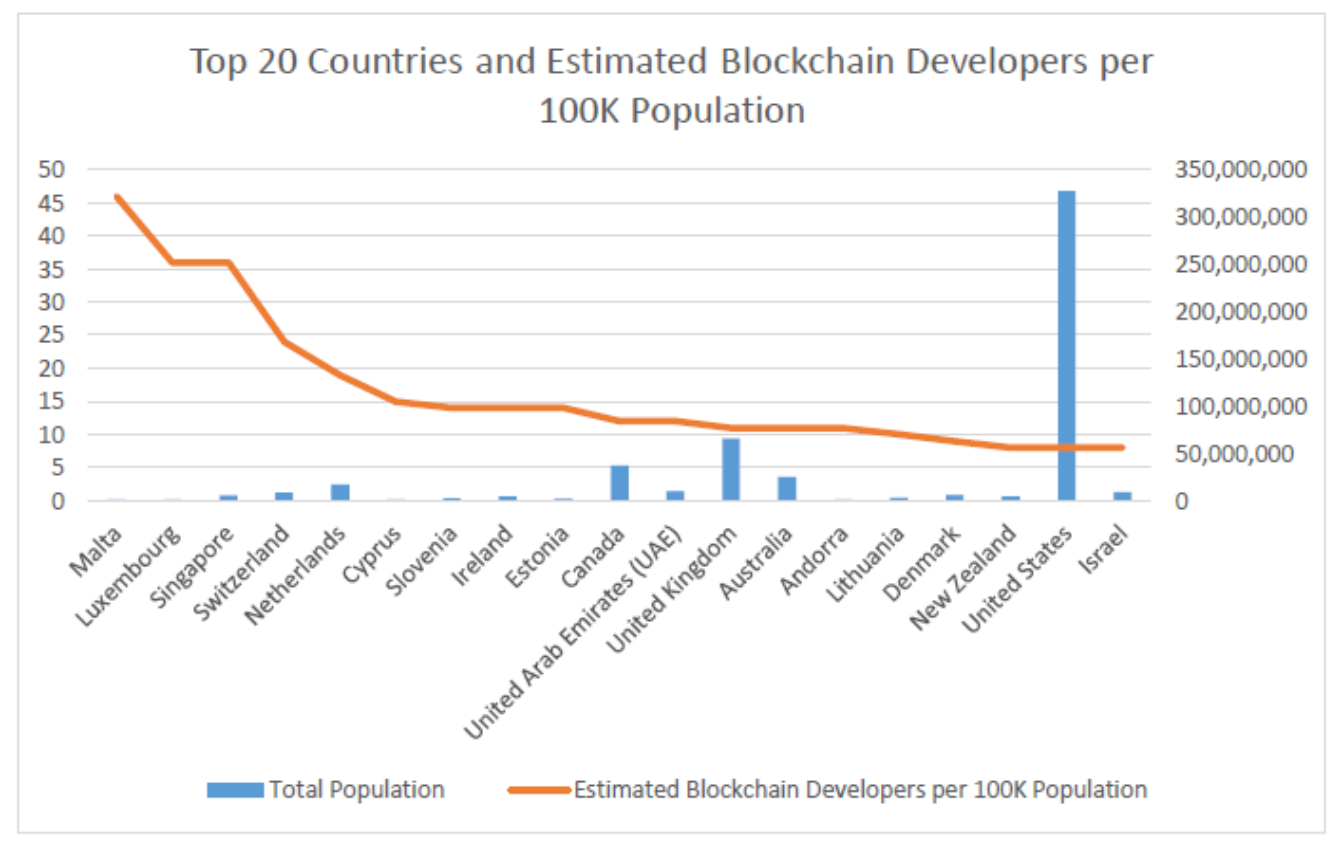

Figure 7. Estimated global blockchain developers per 100k population (Top 20 Countries)

\section{Blockchain applications}

Governments in Dubai, United States, Korea China and India are planning to launch public services using Blockchain to prevent fraud and better data management. Blockchain is disrupting all sectors and going to become most widely adopted technology of this era. It is having vast area of applications although some of the applications of Blockchain are listed below

1. Land Registry: The Swedish Lantmäteriet has successfully tested a Blockchain Platform for Land Registry with the help of SBAB, Telia Company, Landshypotek Bank, Kairos Future and ChromaWay. The Land Registry System (Figure 8) stores purchase/sale bills and contracts, signatures of parties, their identity documents and ownership information in Blockchain. Edition of records are allowed through administrative interface only but record all the transactions in Blockchain, which can be viewed by all stakeholders like buyers, sellers, agents, banks including public (Kempe, 2017). Ghana government and IBM have signed Memorandum of Understanding (MoU) to develop Blockchain based Platform (ghanaweb.com, 2018). An Indian state government, Andhra Pradesh has also piloted land registry and registered 100,000 land records in Blockchain (Haridas, 2018).

2. International Trade: World Trade Organization (TWO) is looking at various feasibility to bring International Trade in Blockchain (Ganne, 2018). In January 2018 Maersk and IBM come up together to develop Blockchain based solution to Digitize Supply Chains and Improve Global Trade (White, 2018) and in August, 2018 Maersk and IBM Introduce a robust Blockchain Platform called TradeLens with Shipping Solution 90 organizations participated in this solution and 154 million events captured. TradeLens is recording one million trade-based events on daily basis (IBM, 2018). Singapore and Hong Kong are jointly developing Global Trade Connectivity Network (GTCN) using Distributed Ledger Technology (DLT) (Hong Kong Monetary Authority (HKMA), 2017).

3. Customs: The World Customs Organization (WCO) has already initiated feasibility study to transform custom processes into Blockchain. They are exploring the option to join TradeLens platform jointly developed by IBM and Maersk including Global Trade Connectivity Network (GTCN) (Okazaki, 2018). U.S. Customs and Border Protection (CBP) agency is also testing Blockchain based shipment tracking system developed by the Department of Homeland Security (Partz, 2018). Samsung SDS is 
developing a Blockchain based platform for an export and customs clearance system for The Korea Customs Service (KCS) (Das, 2018).

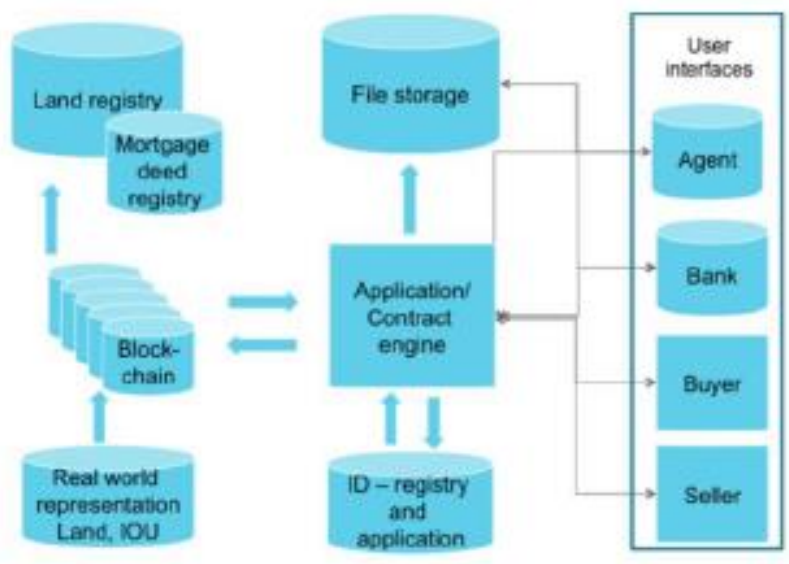

Figure 8. The swedish lantmäteriet land registry blockchain platform

As shown in Figure 9 Banking, Financial Service and Insurance are most disrupted sectors by Blockchain followed by Conglomerate and Automotive sectors, and are the consumers of Blockchain. While Technology sectors are Blockchain platform and service providers in general. We have listed top 50 global public companies in Table 3 who are exploring/adopting Blockchain in their businesses. Blockchain application use cases are also listed along with it.

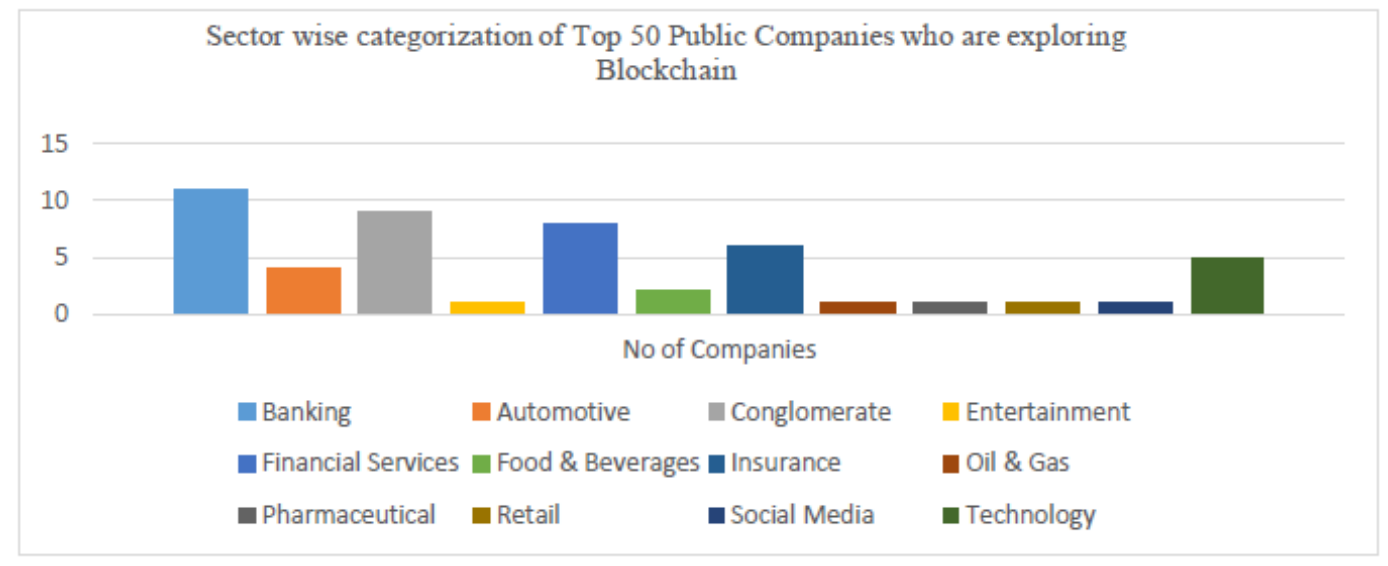

Figure 9. Sector wise categorization of top 50 public companies who are exploring blockchain 


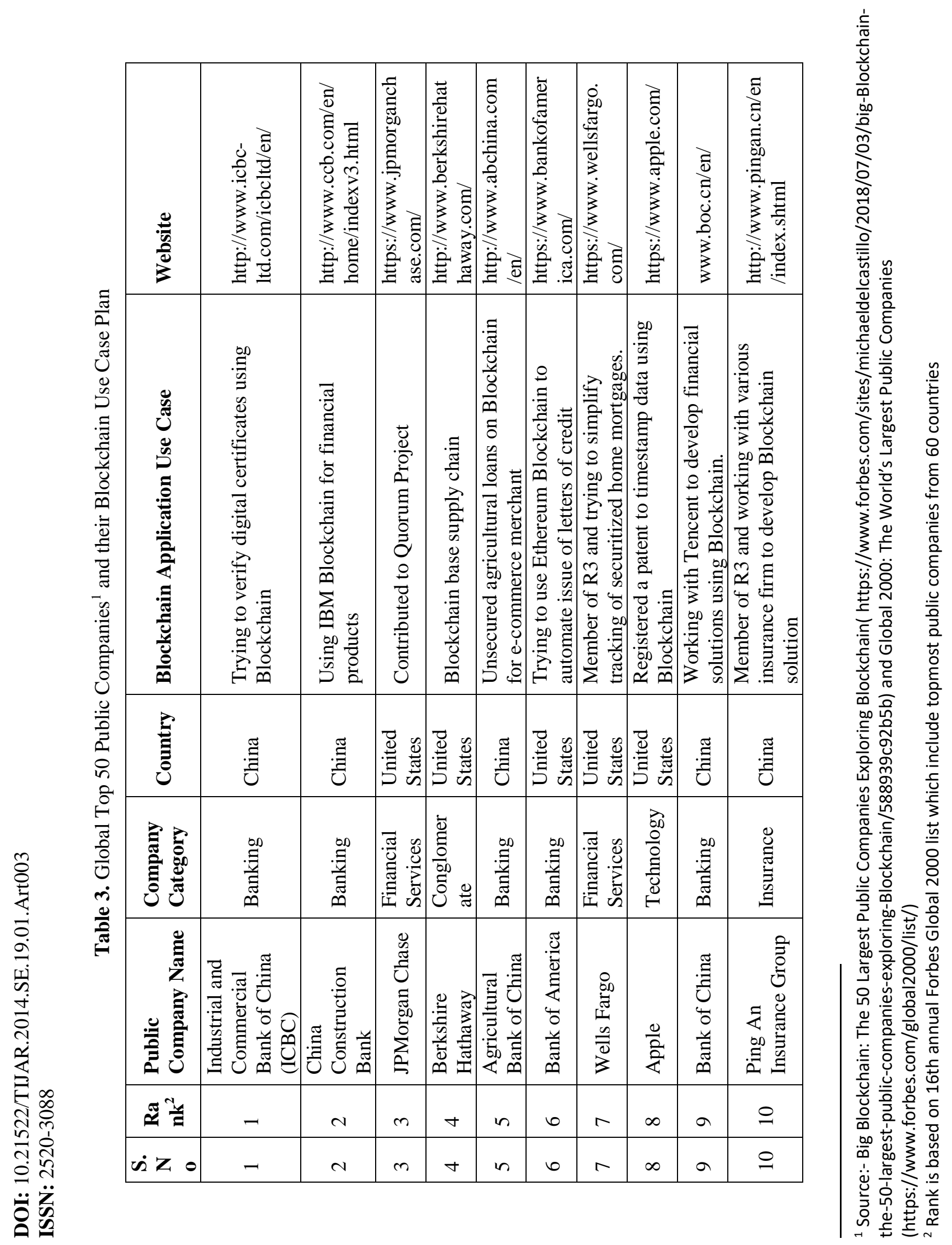


휼

象

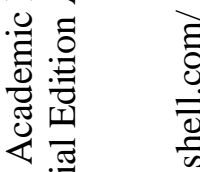

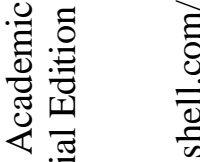

든

(1)

\begin{tabular}{|c|c|c|}
\hline 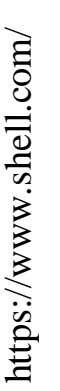 & 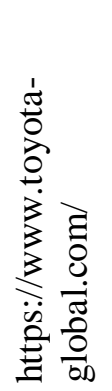 & 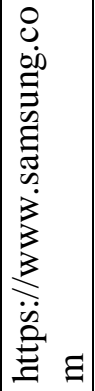 \\
\hline
\end{tabular}

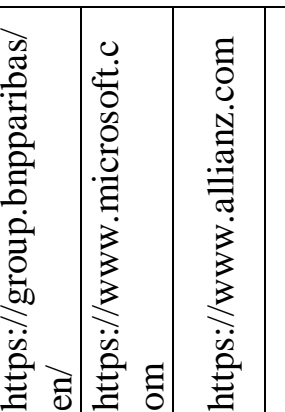

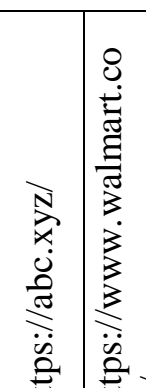

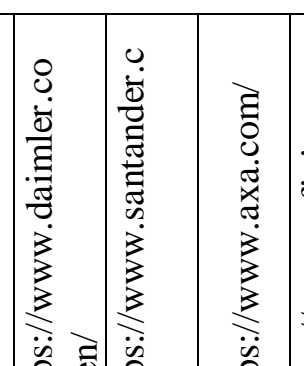

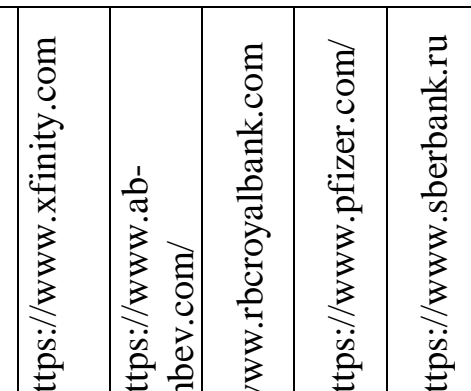

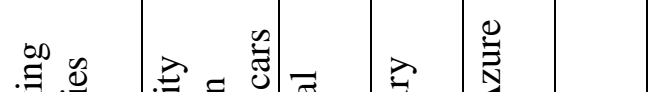

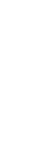

离

:

$\sum_{\substack{0 \\ 0}}^{0} \frac{\sqrt{0}}{0} \cdot \frac{0}{0}$

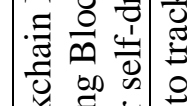

若家

壳

胥

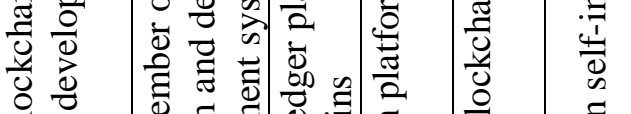

ต ๖

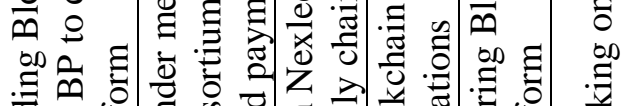

:

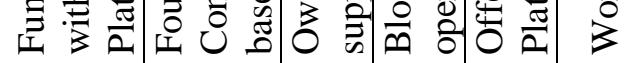

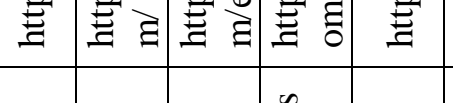

- $=$

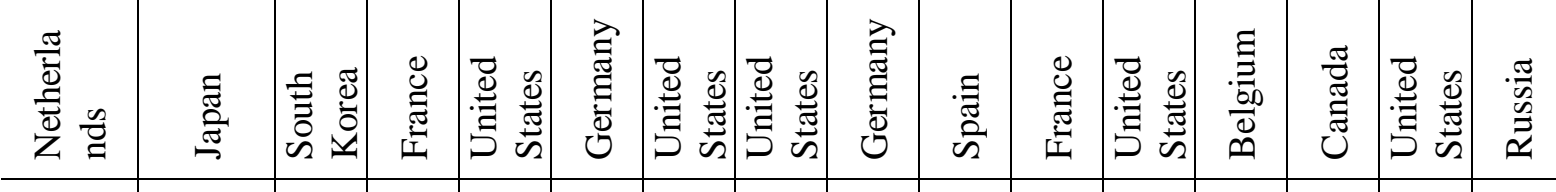

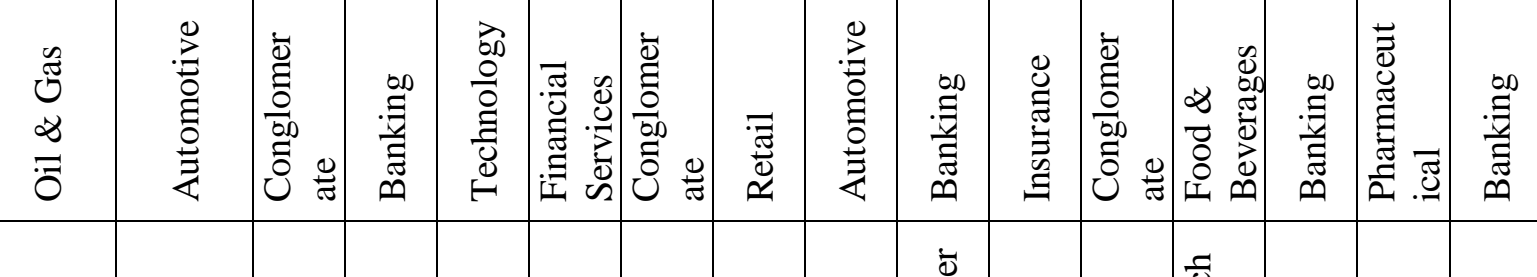

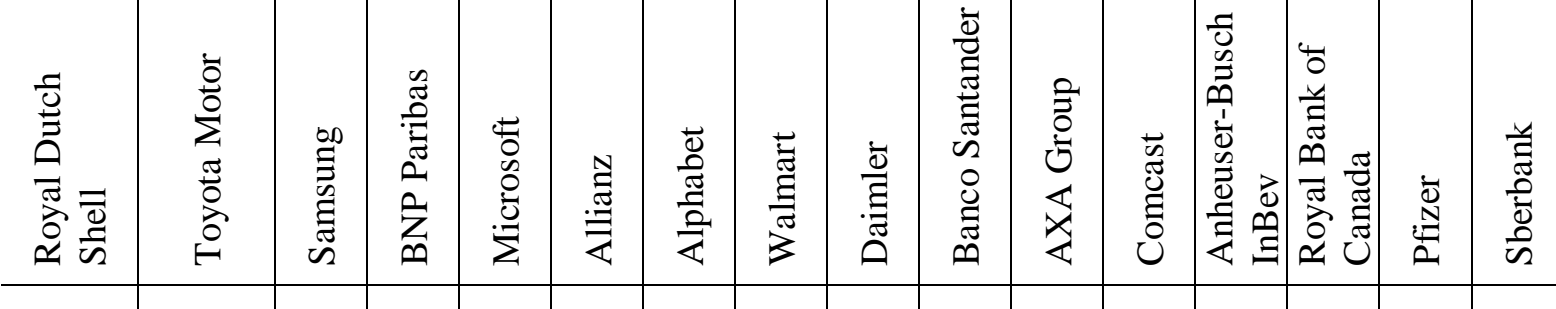

\begin{tabular}{|c|c|c|c|c|c|c|c|c|c|c|c|c|c|c|c|}
\hline$=$ & $\cong$ & \pm & 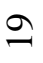 & ㄱ. & $\approx$ & $\tilde{\sim}$ & $\stackrel{\sim}{\sim}$ & ৯े & $\bar{m}$ & $m$ & ণे & $\vec{\gamma}$ & F & $\forall$ & 于 \\
\hline$=$ & $\simeq$ & $m$ & $\Xi$ & $n$ & 0 & I & $\infty$ & $\stackrel{2}{ }$ & 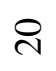 & $\bar{\sim}$ & ปี & $\ddot{\sim}$ & $\stackrel{\searrow}{さ}$ & & 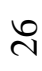 \\
\hline
\end{tabular}




\begin{tabular}{|c|c|c|c|c|c|c|c|c|c|c|c|c|c|c|}
\hline 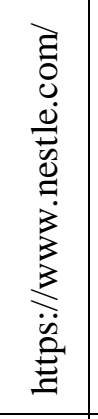 & 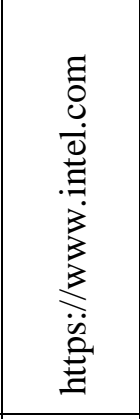 & 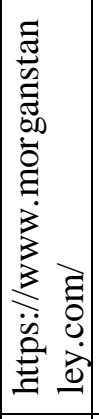 & 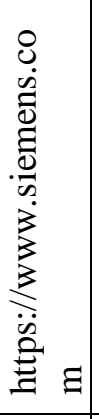 & 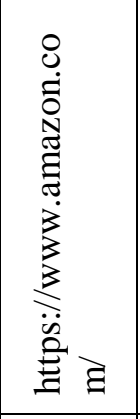 & 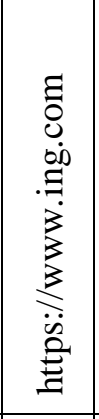 & 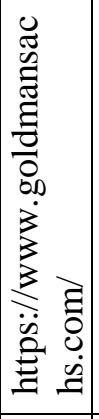 & 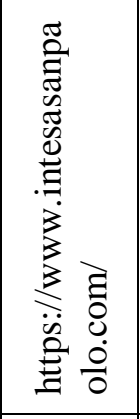 & 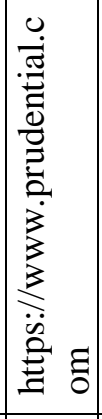 & 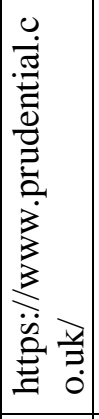 & 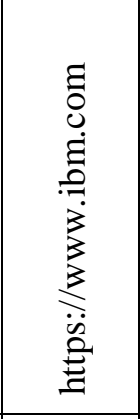 & 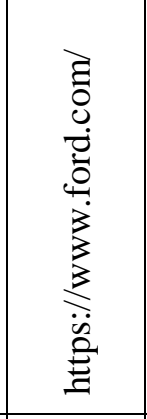 & 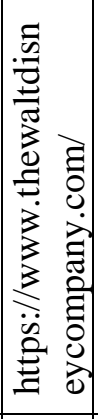 & 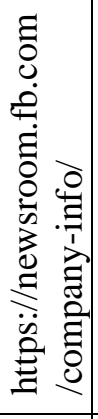 & 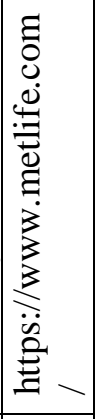 \\
\hline 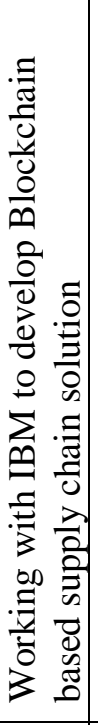 & 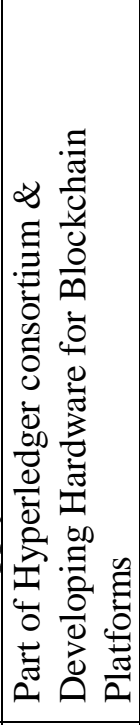 & 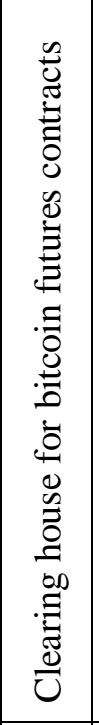 & 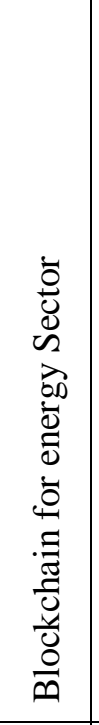 & 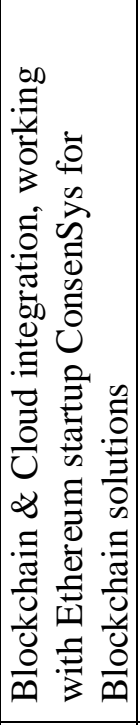 & 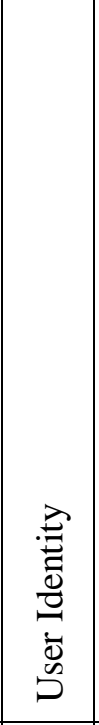 & 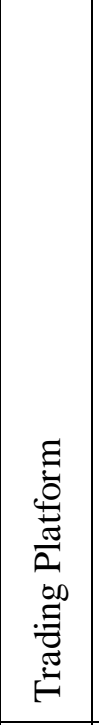 & 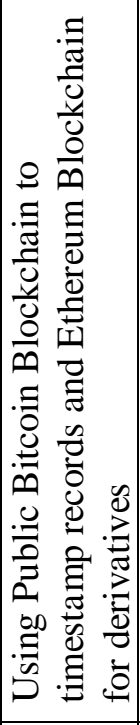 & 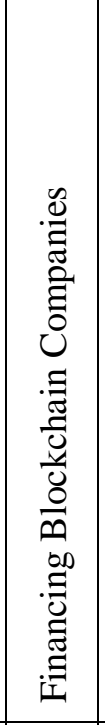 & 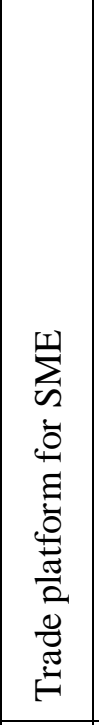 & 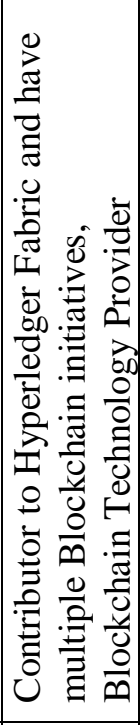 & 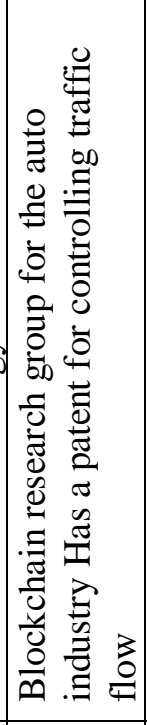 & 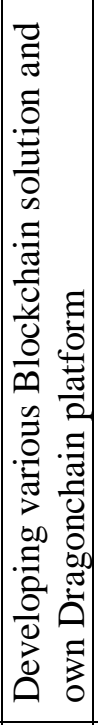 & 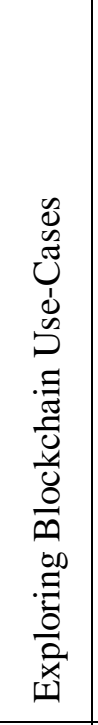 & 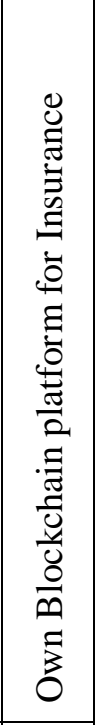 \\
\hline 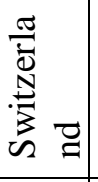 & 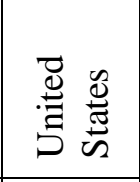 & 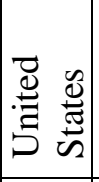 & 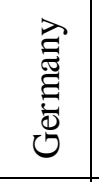 & 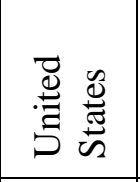 & 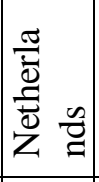 & 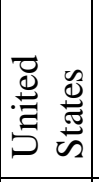 & $\stackrel{\vec{\pi}}{ \pm}$ & 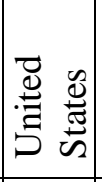 & 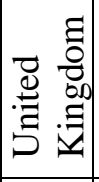 & 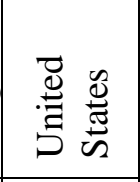 & 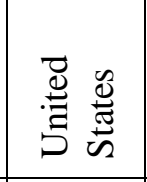 & 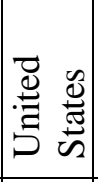 & 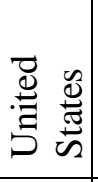 & 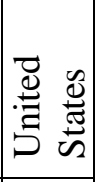 \\
\hline 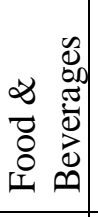 & $\begin{array}{l}\text { के } \\
0 \\
0 \\
0 \\
0 \\
0 \\
.0\end{array}$ & 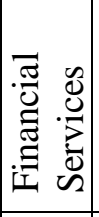 & 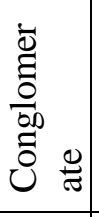 & 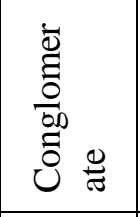 & 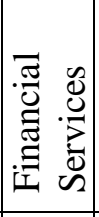 & 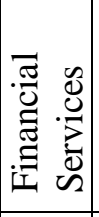 & 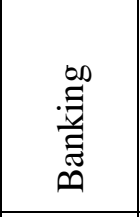 & 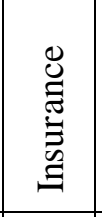 & 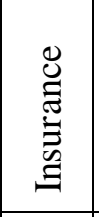 & 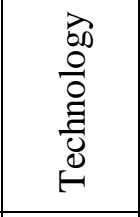 & 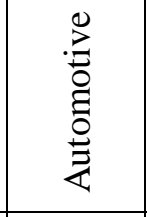 & 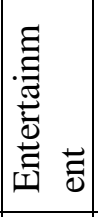 & 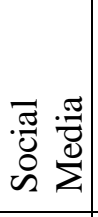 & 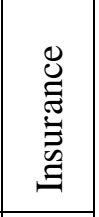 \\
\hline $\begin{array}{l}\stackrel{0}{\tilde{n}} \\
\text { z }\end{array}$ & $\stackrel{\bar{\Xi}}{\Xi}$ & 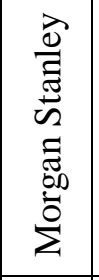 & 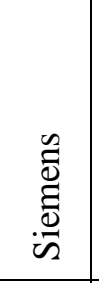 & 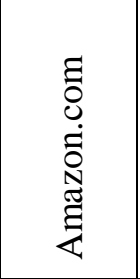 & 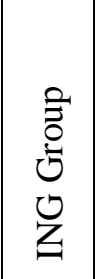 & 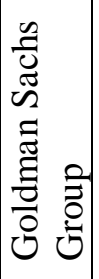 & 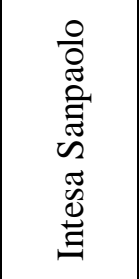 & 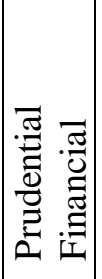 & 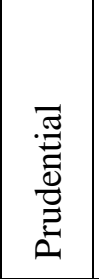 & $\sum_{\oplus}$ & 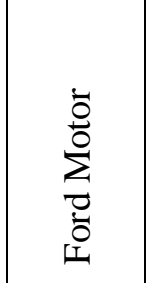 & 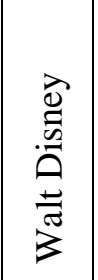 & 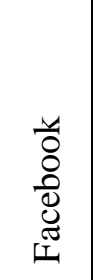 & 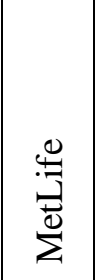 \\
\hline$\stackrel{\infty}{+}$ & 午 & $\stackrel{n}{n}$ & $n$ & in & $\curvearrowleft$ & 8 & 6 & 8 & రి & 6 & 6 & $\sim$ & $\hat{\imath}$ & $\sim$ \\
\hline$\widehat{\sim}$ & $\stackrel{\infty}{\sim}$ & নे & $m$ & $m$ & N & $m$ & m & $m$ & b & $m$ & $m$ & ले & $\bar{y}$ & $\forall$ \\
\hline
\end{tabular}

은 


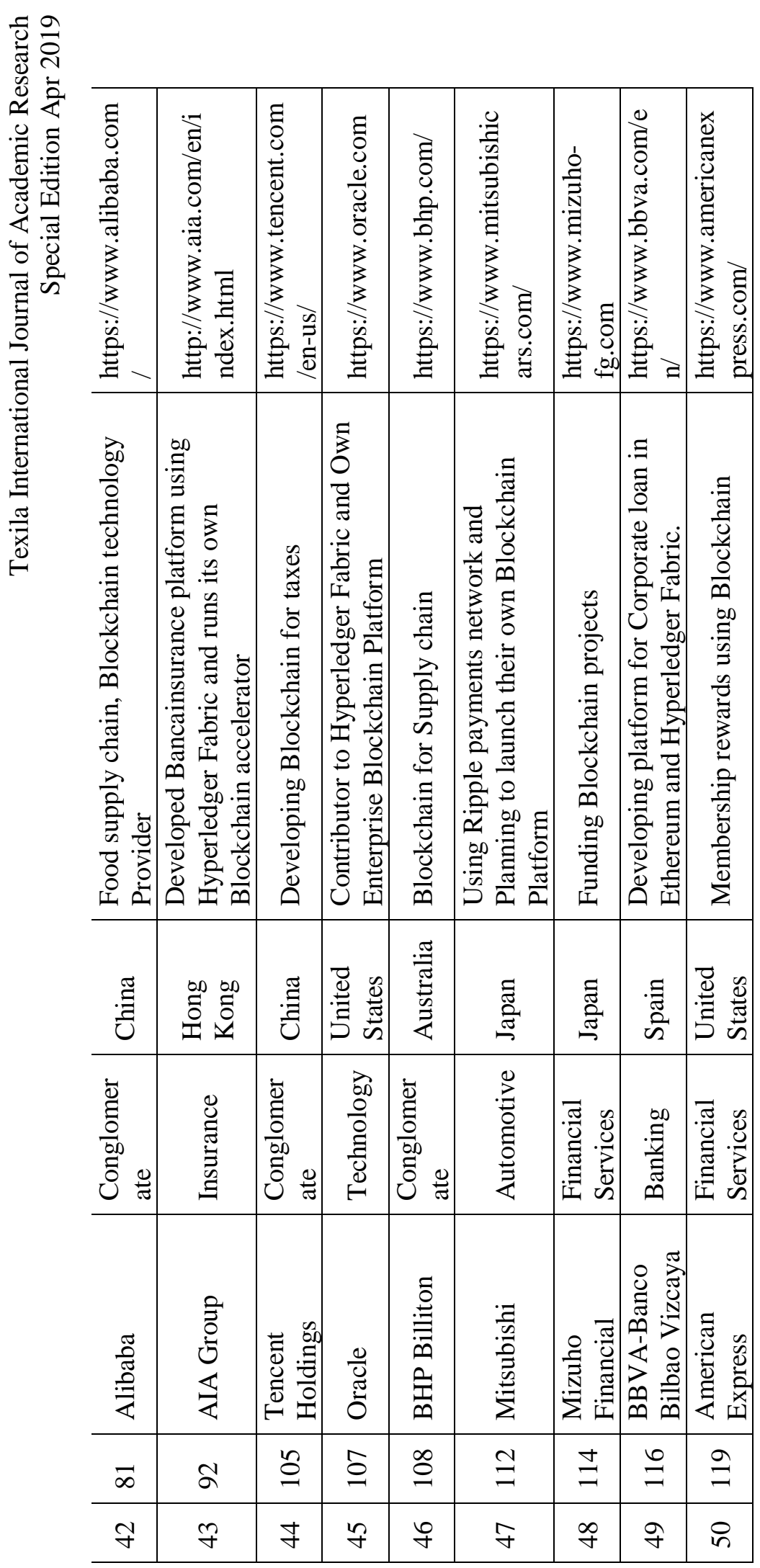


DOI: $10.21522 /$ TIJAR.2014.SE.19.01.Art003

ISSN: 2520-3088

\section{Conclusion}

This is certain that Blockchain is new technology and disrupting almost all sectors. Various organizations are pouring lots of money into Blockchain Platform development and transforming their businesses and operation by adopting Blockchain but the big question on hand is, why? Because these organizations knows that, there are various complexities and loopholes in their existing systems, which Blockchain is addressing. Data is stored in distributed ledger, secured using cryptographic functions and almost temper resistance. Blockchain promote trust and transparency between participating parties and elements need of third parties that is huge cost saving and operational plus point. Smart contracts are the digital agreements between parties and a new way of doing business while Code is the law in Blockchain and records in ledger are proof of an event.

\section{References}

[1]. Bertoni, G., Daemen, J., Peeters, M., \& Assche, G. V. (2009). Keccak sponge function family main document. NIST. Retrieved 2018, from http://131002.net/data/papers/AK09.pdf

[2]. Bitcoin Community. (2018). Network. Retrieved from en.bitcoin.it: https://en.bitcoin.it/wiki/Network

[3]. Bittle, S. (2017, 10 30). Job Postings for Blockchain Skills Double Over 2016. Retrieved from burningglass.com: https://www.burning-glass.com/blog/job-postings-blockchain-skills-double-2016/

[4]. Buchmann, J., Dahmen, E., Ereth, S., Hülsing, A., \& Rückert, M. (2011). On the security of the Winternitz onetime signature scheme. International Conference on Cryptology in Africa (pp. 363-378). Berlin, Heidelberg: Springer. [5]. Cloud Standards Customer Council. (2017). Cloud Customer Architecture for Blockchain. Object Managment Group (OMG).

[6]. Das, S. (2018, September 17). https://www.ccn.com/samsung-sds-to-power-worlds-first-exports-customsclearance-blockchain-in-korea/. Retrieved from ccn.com: https://www.ccn.com/samsung-sds-to-power-worlds-firstexports-customs-clearance-blockchain-in-korea/

[7]. Dinh, T. T., Wang, J., Chen, G., Liu, R., Ooi, B. C., \& Tan, K.-L. (2017). Blockbench: A framework for analyzing private blockchains. In Proceedings of the 2017 ACM International Conference on Management of Data, 1085-1100.

[8]. Dworkin, M. J. (2015). SHA-3 standard: Permutation-based hash and extendable-output functions. United States: NIST FIPS.

[9]. Ethereum Community. (2018). devp2p Application Protocol. Retrieved from github.com/ethereum/: https://github.com/ethereum/devp2p/blob/master/devp2p.md

[10]. Fernàndez-València, R., Caube, J., \& Vila, A. (2018). Cryptography Working Group Introduction to Blockchain Technology. bigdatabcn.com, 1-18.

[11]. Filatov, T. (2018, 09 30). Blockchain developers worldwide stats (absolute vs relative to population). Retrieved from Analytics, Blockchain Developers: https://www.dappros.com/201809/blockchain-developers-worldwide-statsabsolute-vs-relative-to-population/

[12]. Ganne, E. (2018). Can Blockchain revolutionize international trade? World Trade Organization (WTO).

[13]. ghanaweb.com. (2018, July). Blockchain technology to revolutionise land administration processes. Retrieved from ghanaweb.com: https://www.ghanaweb.com/GhanaHomePage/business/Blockchain-technology-torevolutionise-land-administration-processes-666920

[14]. Glabb, R., Imbert, L., Jullien, G., Tisserand, A., \& Veyrat-Charvillon, N. (2007). Multi-mode operator for SHA2 hash functions. Journal of Systems Architecture, 127-138.

[15]. Haridas, S. (2018). This Indian City Is Embracing BlockChain Technology -- Here's Why. Retrieved from forbes.com: $\quad$ https://www.forbes.com/sites/outofasia/2018/03/05/this-indian-city-is-embracing-blockchaintechnology-heres-why/\#437312dd8f56

[16]. Hileman, D. G., \& Rauchs, M. (2017). Global Blockchain Benchmarking Study. Cambridge Centre for Alternative Finance. Cambridge, United Kingdom: SSRN Electronic Journal.

[17]. Hiran, K. K., Henten, A., Shrivas, M. K., \& Doshi, R. (2018). Hybrid EduCloud Model in Higher Education: The case of Sub-Saharan Africa, Ethiopia. 2018 IEEE 7th International Conference on Adaptive Science \& Technology (ICAST) (pp. 1-9). Accra, Ghana: IEEE. 
[18]. Hong Kong Monetary Authority (HKMA). (2017, November 15). Hong Kong and Singapore launch a joint project on cross-border trade and trade finance platform. Retrieved from hkma.gov.hk: https://www.hkma.gov.hk/eng/key-information/press-releases/2017/20171115-6.shtml

[19]. HowToToken Team. (2018). Blockchain Developer Salaries - 2018 Report. Retrieved from howtotoken.com: https://howtotoken.com/career/blockchain-developer-salaries-2018-report/

[20]. Hyperledger. (2018). Gossip data dissemination protocol. Retrieved from hyperledger-fabric.readthedocs.io: https://hyperledger-fabric.readthedocs.io/en/release-1.3/gossip.html

[21]. IBM. (2018, August 9). Maersk and IBM Introduce TradeLens Blockchain Shipping Solution. Retrieved from newsroom.ibm.com: https://newsroom.ibm.com/2018-08-09-Maersk-and-IBM-Introduce-TradeLens-BlockchainShipping-Solution

[22]. Kempe, M. (2017). The Land Registry in the blockchain - testbed. Retrieved from chromaway.com: https://chromaway.com/papers/Blockchain_Landregistry_Report_2017.pdf

[23]. Lin, I.-C., \& Liao, T.-C. (2017). A Survey of Blockchain Security Issues and Challenges. IJ Network Security, Vol. 19(Issue 5), 653-659.

[24]. Lovelock, J.-D., Reynolds, M., Granetto, B., \& Kandaswamy, R. (2017). Forecast: Blockchain Business Value, Worldwide, 2017-2030. Stamford, USA: Gartner.

[25]. Mearian, L. (2018). Blockchain moves into top spot for hottest job skills. Retrieved from computerworld.com: https://www.computerworld.com/article/3235972/it-careers/blockchain-moves-into-top-spot-for-hottest-job-

skills.html

[26]. Michael, J., Cohn, A., \& Butcher, J. R. (2018). BlockChain technology. The Journal, 34-44.

[27]. Miscione, G., Ziolkowski, R., Zavolokina, L., \& Schwabe, G. (2018). Tribal governance: The business of blockchain authentication. In Proceedings of the 51st Hawaii International Conference on System Sciences. Hawaii: SSRN.

[28]. Nofer, M., Gomber, P., Hinz, O., \& Schiereck, D. (2017). Blockchain. Business \& Information Systems Engineering, Vol. 50(Issue No.-3), 183-187.

[29]. Okazaki, Y. (2018). Unveiling the Potential of Blockchain for Customs. World Customs Organization.

[30]. Partz, H. (2018). US Customs and Border Protection to Test Blockchain Shipment Tracking System. Retrieved from cointelegraph.com: https://cointelegraph.com/news/us-customs-and-border-protection-to-test-blockchainshipment-tracking-system

[31]. Pawczuk, L., Massey, R., \& Schatsky, D. (2018). Deloitte's 2018 global blockchain survey. London, United Kingdom: Deloitte Consulting LLP.

[32]. Percival, C., \& Josefsson, S. (2016). Patent No. No. RFC 7914.

[33]. PricewaterhouseCoopers (PwC) Ltd. (2018). PwC's Global Blockchain Survey 2018. Hong Kong: PricewaterhouseCoopers (PwC) Ltd.

[34]. Saarinen, M. J., \& Aumasson, J.-P. (2015). Patent No. IETF RFC 7693. doi:DOI: 10.17487/RFC7693

[35]. Shrivas, M. K., \& Yeboah, D. T. (2017). A Critical Review of Cryptocurrency Systems. TEXILA INTERNATIONAL JOURNAL OF ACADEMIC RESEARCH, Vol. 4(Issue 2), 116-131. doi:DOI: 10.21522/TIJAR.2014.04.02.Art012

[36]. statista.com. (2018, 04). Gross domestic product (GDP) ranking by country 2017 (in billion U.S. dollars). Retrieved from statista.com: https://www.statista.com/statistics/268173/countries-with-the-largest-gross-domesticproduct-gdp/

[37]. Swedberg, R. (2018). On the Uses of Exploratory Research and Exploratory. Retrieved from people.soc.cornell.edu/swedberg:

http://people.soc.cornell.edu/swedberg/On\%20the\%20Uses\%20of\%20Exploratory\%20Research\%20and\%20Explor atory\%20Studies\%20in\%20Social\%20Science.pdf

[38]. Tama, B. A., Kweka, B. J., Park, Y., \& Rhee, K.-H. (2017). A critical review of blockchain and its current applications. In Electrical Engineering and Computer Science (ICECOS), 2017 International Conference on, pp. 109113. 
DOI: 10.21522/TIJAR.2014.SE.19.01.Art003

ISSN: $2520-3088$

[39]. Walters, S. (2018). Blockchain Salaries: How Much Do Blockchain Professionals Earn? Retrieved from bitcoinmarketjournal.com: https://www.bitcoinmarketjournal.com/blockchain-salary/

[40]. White, M. (2018, January 16). Digitizing Global Trade with Maersk and IBM. Retrieved from ibm.com: https://www.ibm.com/blogs/blockchain/2018/01/digitizing-global-trade-maersk-ibm/

[41]. Zheng, Z., Xie, S., Dai, H., Chen, X., \& Wang, H. (2017). An overview of blockchain technology: Architecture, consensus, and future trends. In Big Data (BigData Congress), 2017 IEEE International Congress on, 557-564.

[42]. Zheng, Z., Xie, S., Dai, H.-N., \& Wang, H. (2016). Blockchain challenges and opportunities: A survey. International Journal of Web and Grid Services, 1-25. 

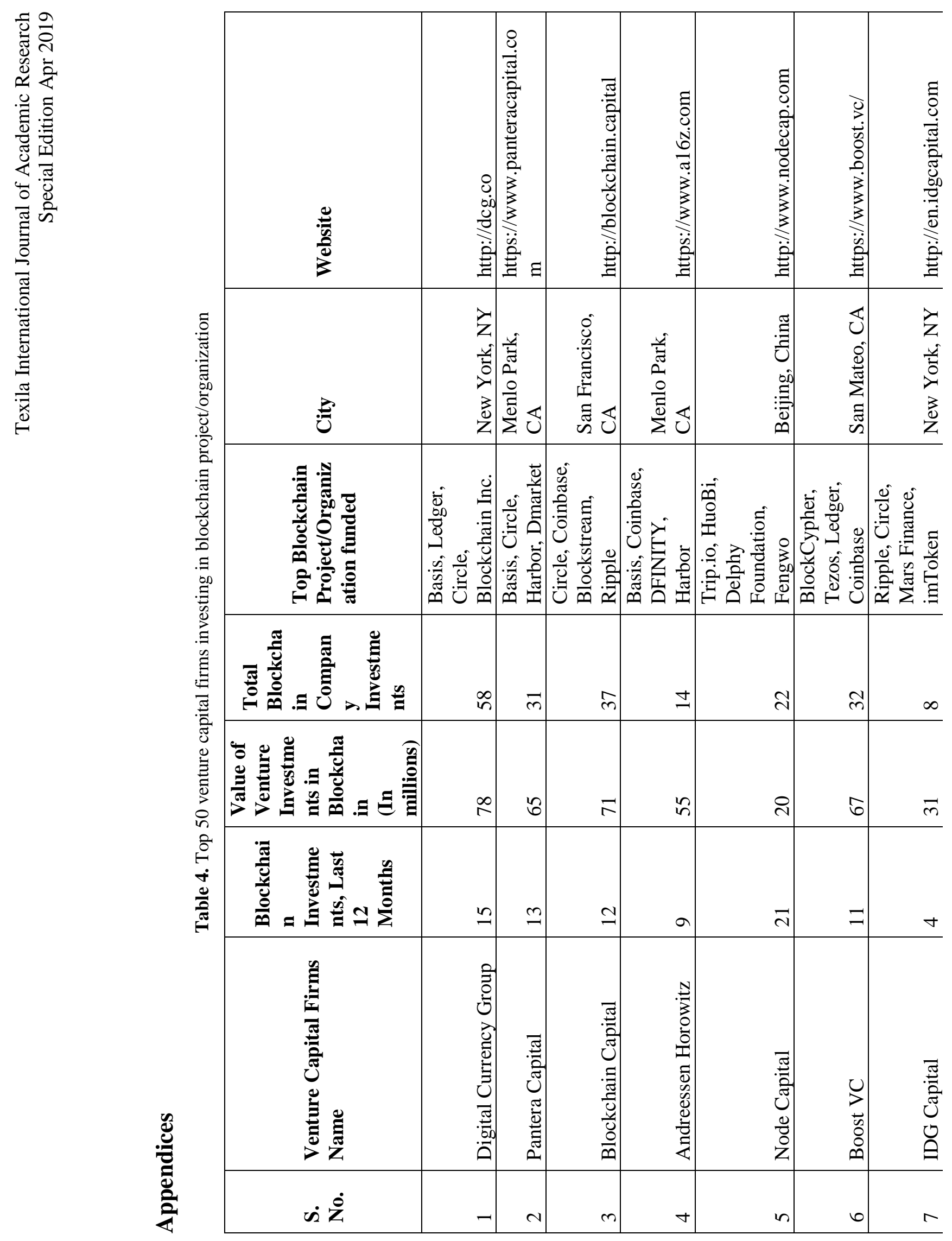


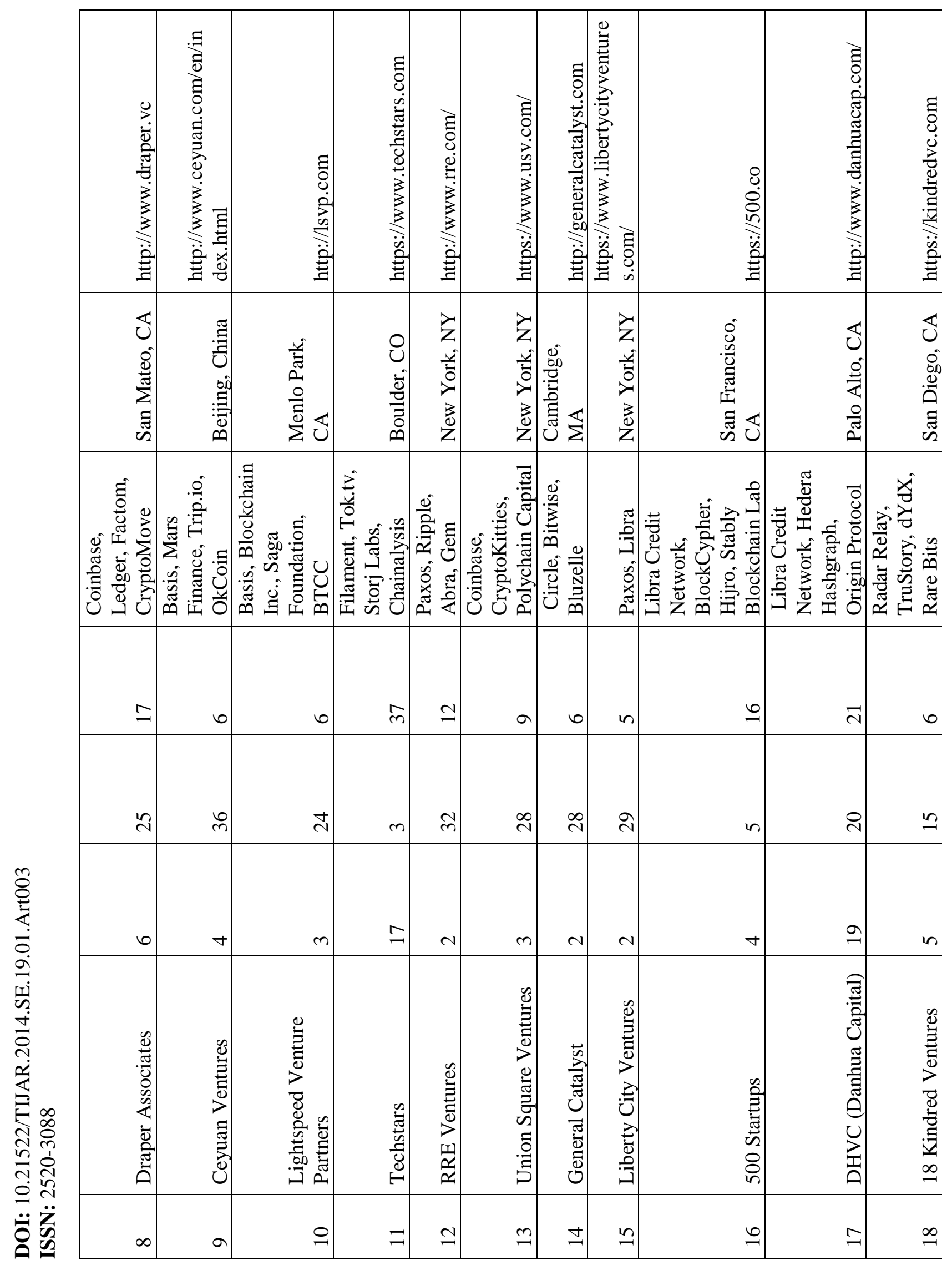




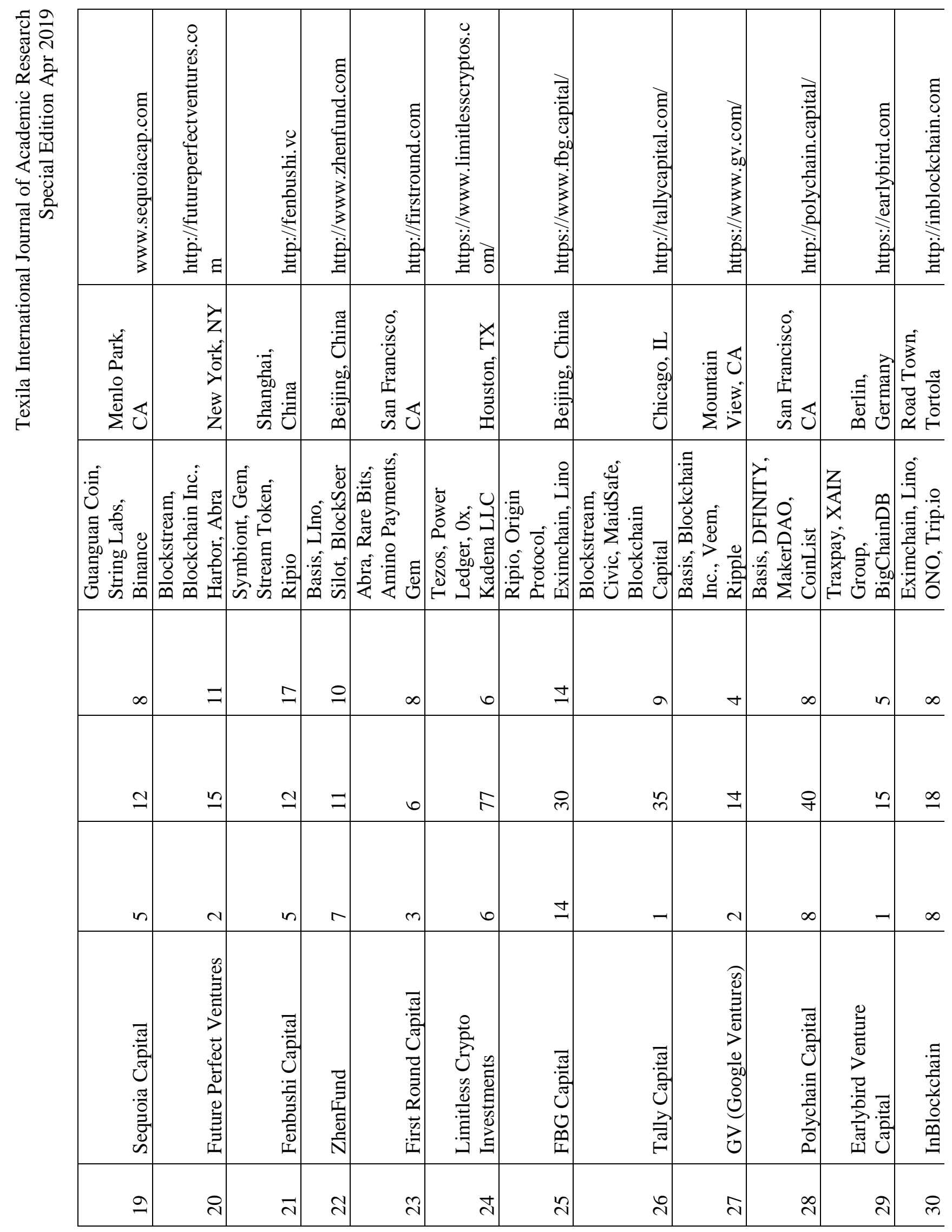




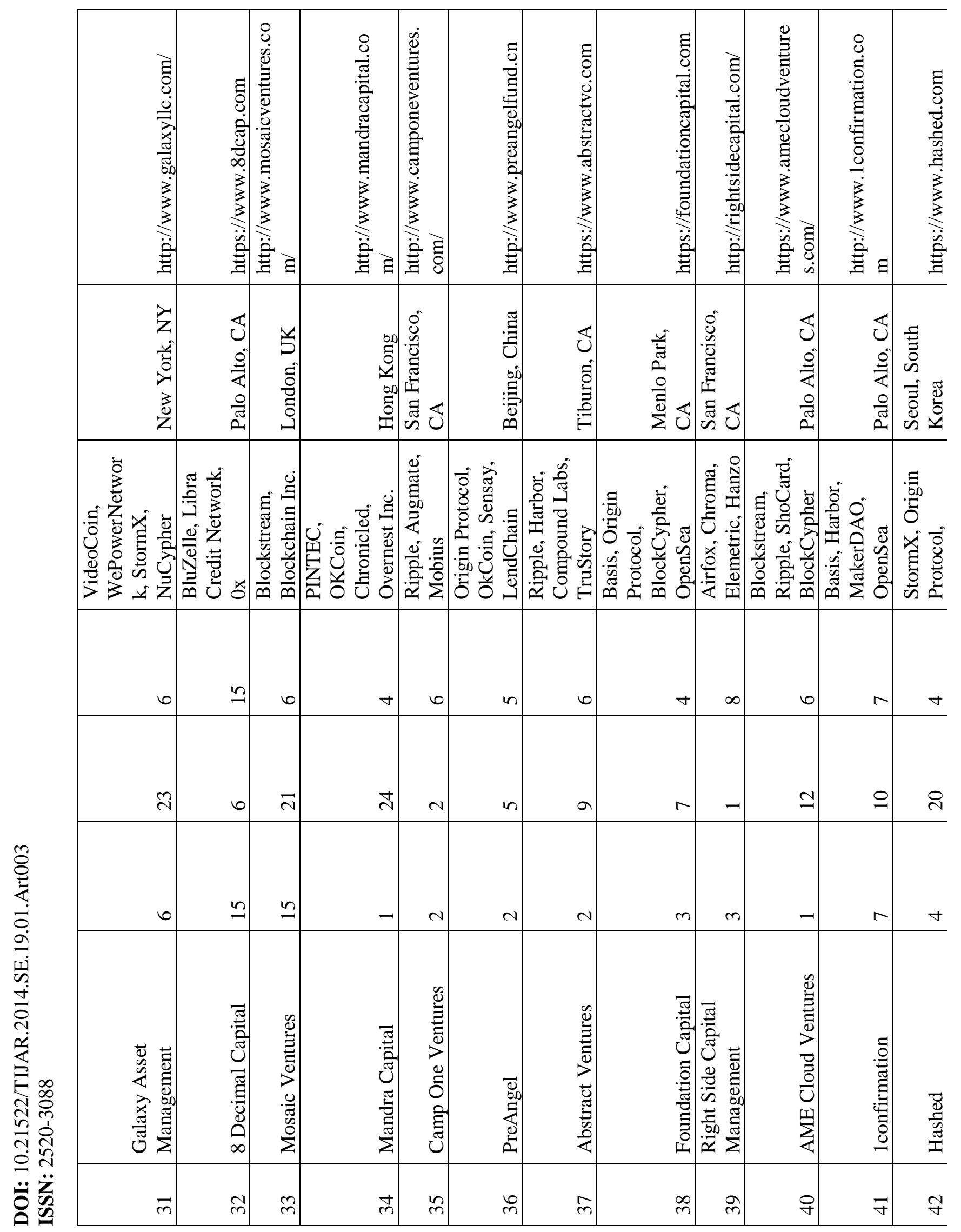




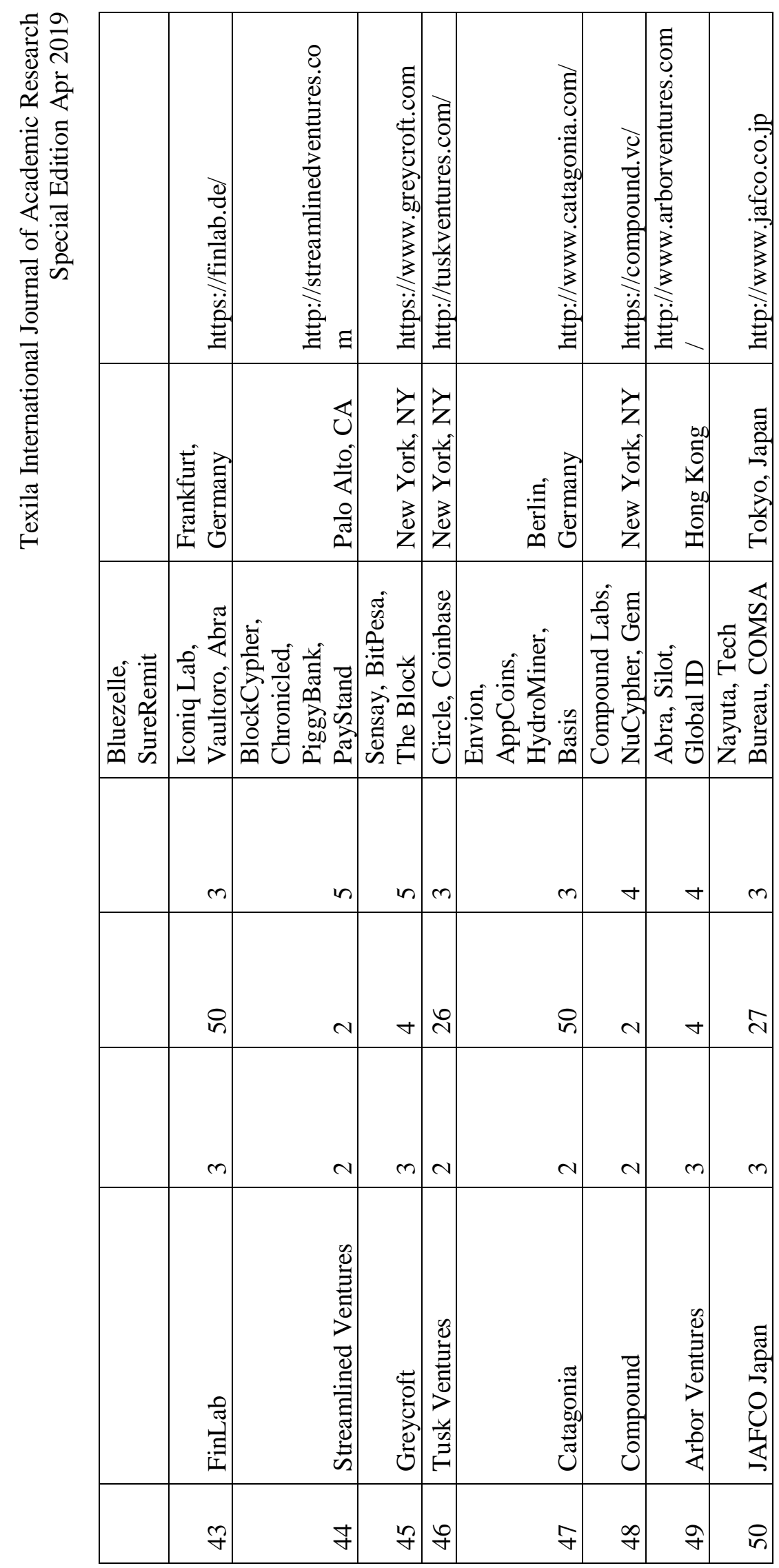

